دور الأسرة في اختيار العاب أطفالها وعلاقته بإدارة الدخل المالي

\author{
إعداد \\ أفناف محمد عمر بسركي \\ قسم السكن وإدارة المنزل \\ كلية الفنون والتصميم الداخلي_جامعة أم القرى
}

مجلة بحوث التربية النوعية - جامعة المنصورة

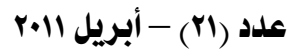




\section{دور الأسرة في اختيار العاب أطفالها وعلاقته بإدارة الدخل المالي}

إعداد

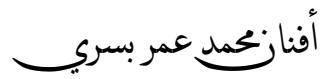

$$
\begin{aligned}
& \text { قسم السكن وإدارة المنزل }
\end{aligned}
$$

كلية الفنون والتصميم الداخلي_جامعة أم المزلئر القرى

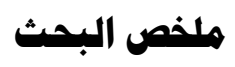

تهدف هذه الدراسة إلى الكشف عن العلاقة بين دور الأسرة يِّ إختيار ألعاب أطفالها، وإدارة

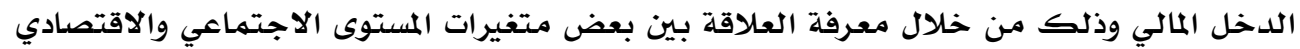

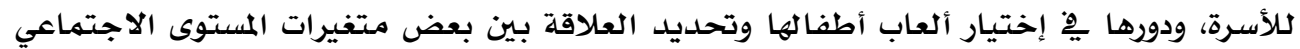

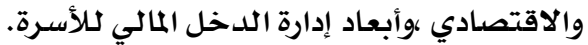

تكونت عينة البحث من عينة قصديه من أرياب وريات أسر سعوديين من مستويات إجتماعية

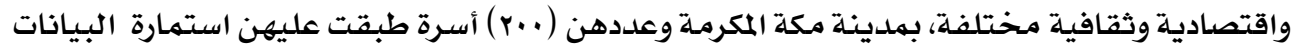

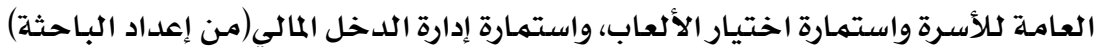
وأسفرت نتائج الدراسة عن وجود علاقة إرتباطية موجبة بين بعض متغيرات المستوىى

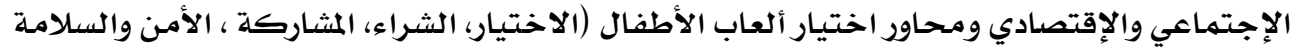

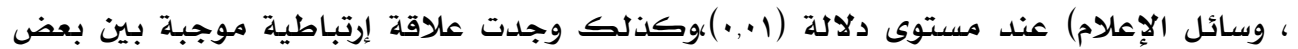

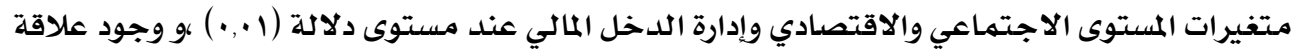

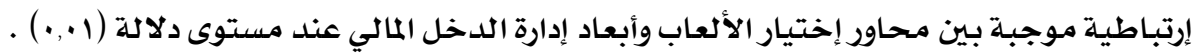
وأوصت الدراسة بضرورة عمل برامـج إرشادية للأسر للتعرف على الأسس العلمية ِِّ اختيار

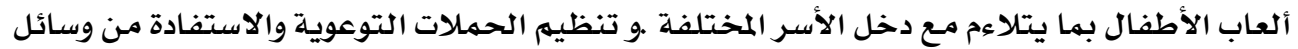

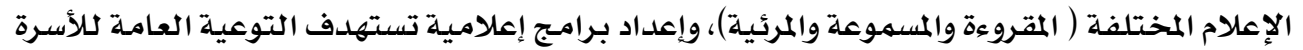

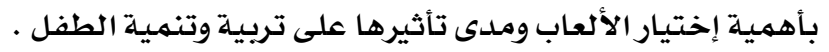




\section{Abstract}

\section{THE ROLE OF THE FAMILY IN THE CHOICE OF CHILDREN TOYS, AND ITS RELATION WITH FAMILY FINANCIAL INCOME MANAGEMENT}

The object of this study was to discover the relation between The Role of The Family in the Choice of Children Toys, and Family Financial Income Management, through discovering the relation between some social ,economical variables to the family, and it's role in the Choice of Children Toys, and the dimensions of family financial income management.

A random sample from different social, economical, cultural Saudi house wives in Makkah has been chosen the size of the sample was about (200) single. The researcher used questionnaires to investigate the role of the family in the choice of children toys, and family financial income management. . The research tools which were used were determined in a questionnaire for family general data , a questionnaire for toys' choice, and a questionnaire for financial income management. also a special Statistical treatment has been done to analyze the questionnaire data in order to get the final results. The most important finding were:

1.There are statistically significant differences between social ,economical levels variables and the dimensions of children toy's choice (choice, buying, participation, safe, safety and information media) at the significance level (0.01).

2. There is a positive correlated relationship between social and economic levels variables, and financial income management at the significance level (0.01).

3. There is a positive correlated relationship between the dimensions of children toy's choice and the dimensions of financial income management at the significance level (0.01).

- According to the research findings, the researcher provides some recommendations and suggestions: 
- It is necessary for those who responsible for the preparation of media in the KSA information programs aimed at raising public awareness of the family importance in the children toy's choice, and it's importance affects on children growth and raising.

- To held debates, and training courses to the house wives in order to help them in the way of managing their financial sources in the right way.

- To organize magazines, guiding programs to increase awareness via different audio able, visual and readable information media programs which aimed to raise public awareness of families with the corrected educational methods of choosing suitable children toy's which are suitable with their financial income.

To develop children awareness of the importance of choosing toy's that matches with their ages, and helps them to a widen their knowledge and their horizons 


\title{
دور الأسرة في اختيار العاب أطفالها وعلاقته بإدارة الدخل المالي
}

\author{
إعداد \\ أفنازتحمد عمر بسريكـ \\ قسم السكن وإدارة المنزل \\ كلية الفنون والتصميم الداخلي_جامعة أم المنرل المرى
}

\section{هقدمة ومشكلة البحث:}

يعتبر ميـدان الاقتـــاد المنزلـي علمـاً ومجــالاً يـرتبط ارتباطـاً وثيقـاً بالحيـاة اليوميـة للأسـرة

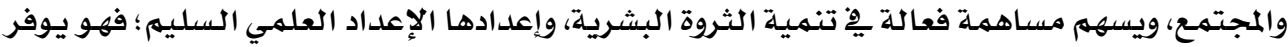

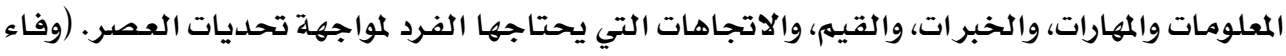

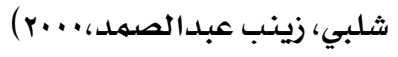

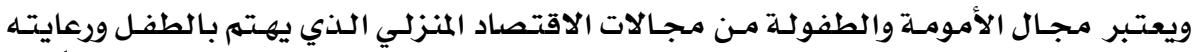

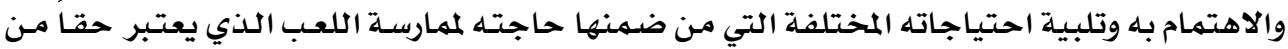

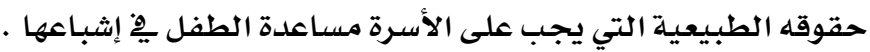

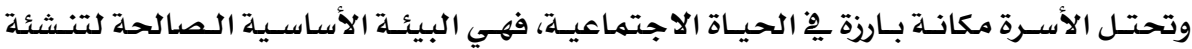

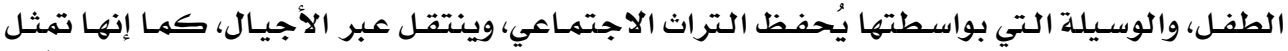

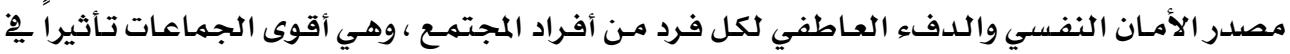

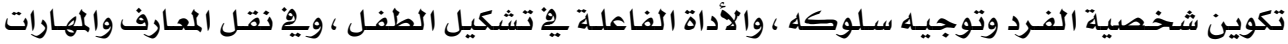

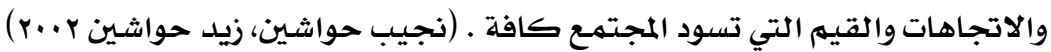

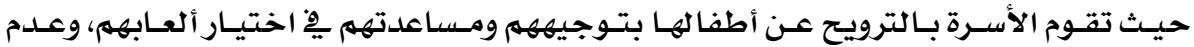

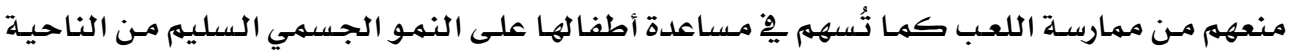

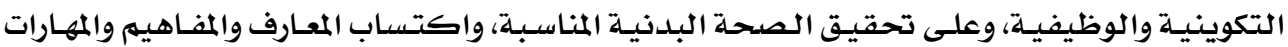

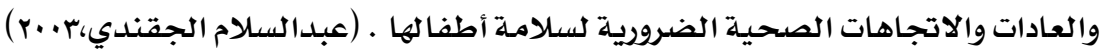
وتقوم الألعاب بلدور كبير فِ حياة الأطفال فحسن اختيارها يساعدهم على تنميـة مهاراتهم لا

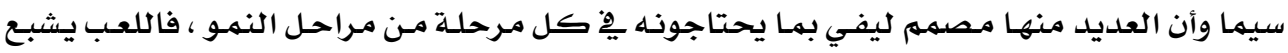

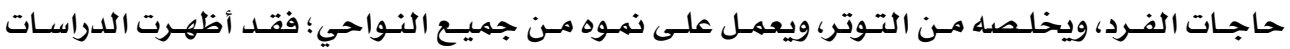

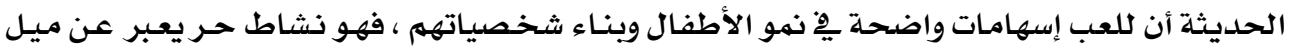

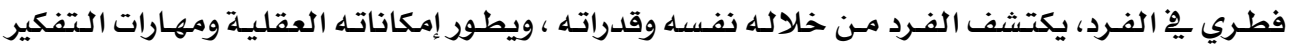

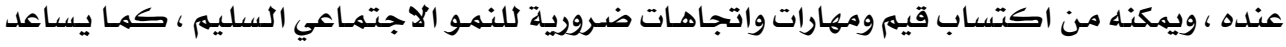

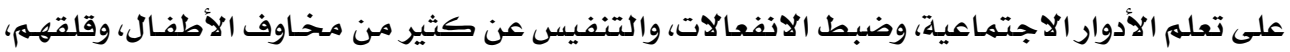

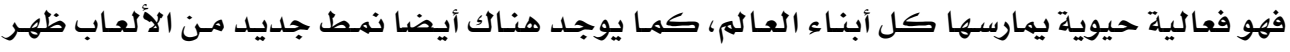




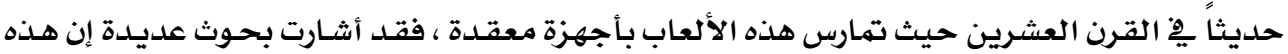

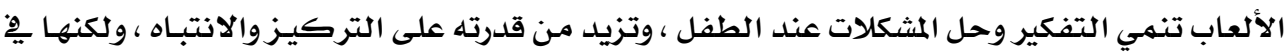

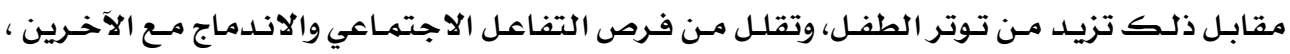

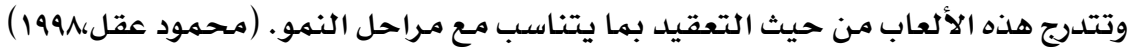

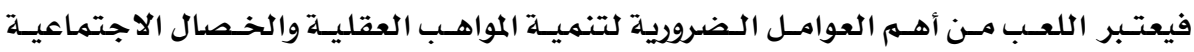

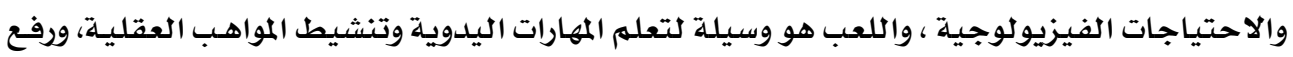

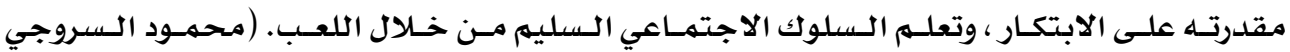

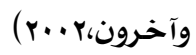

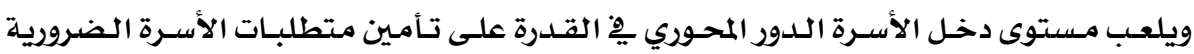

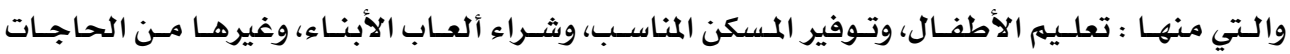

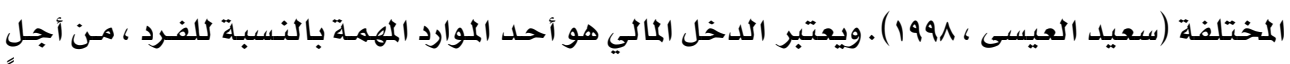

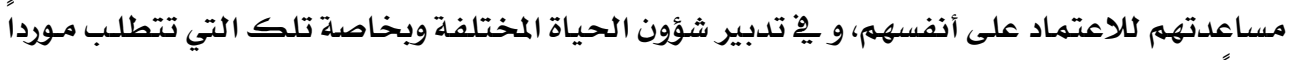

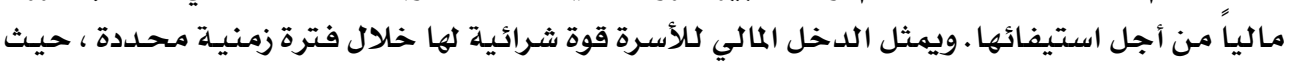

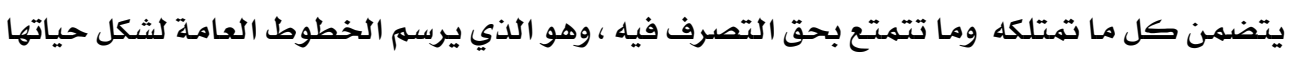

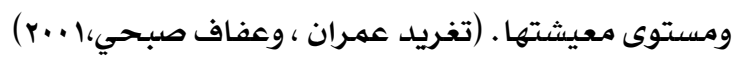

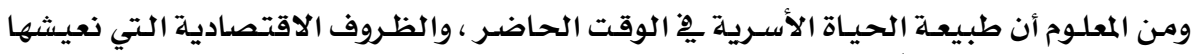

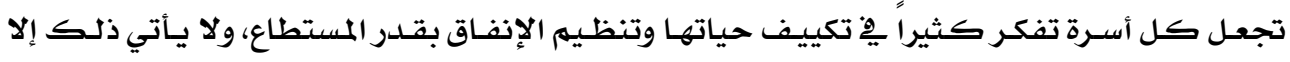

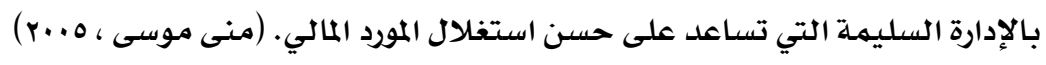

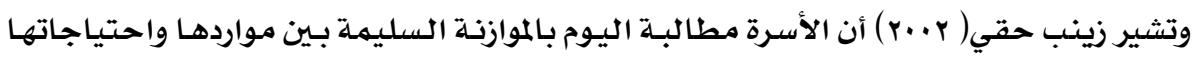

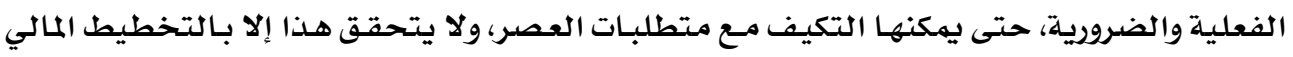

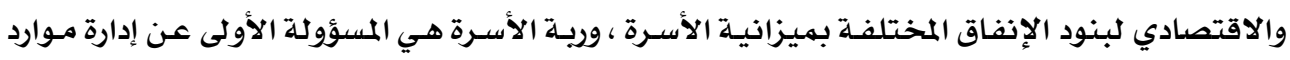

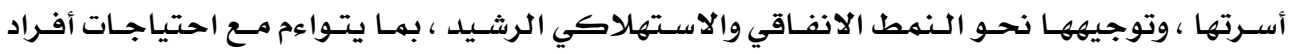

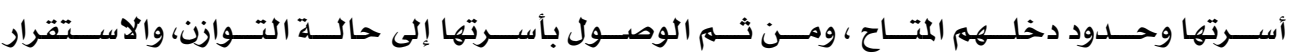

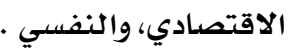

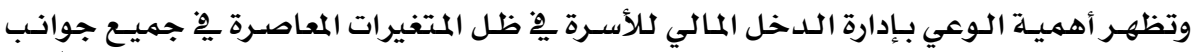

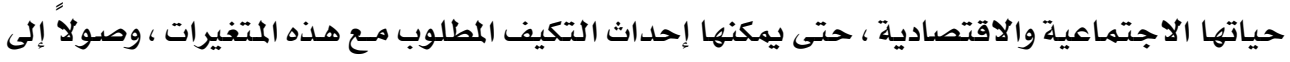

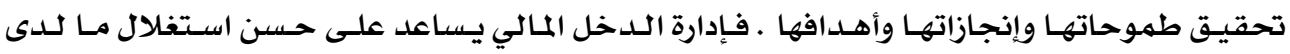

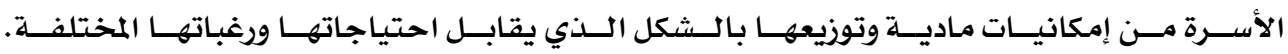

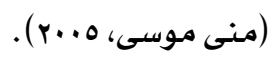

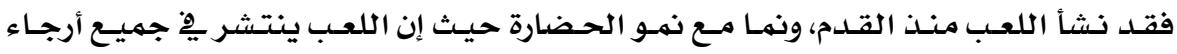

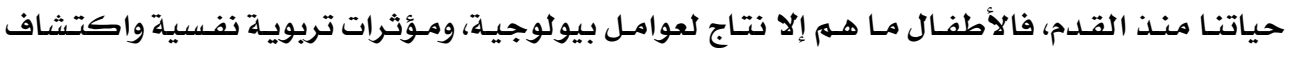

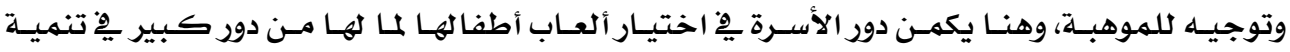




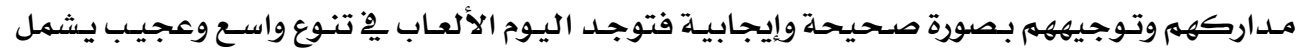

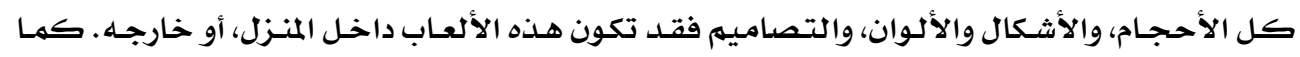

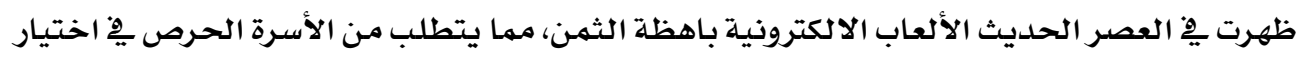
ألعاب أطفالها بها يتاءلاءم مـع دخلها المالي. وعلى ضوء ما سبق تتبلور مشكلة البحث يِ التساؤلات التالية:

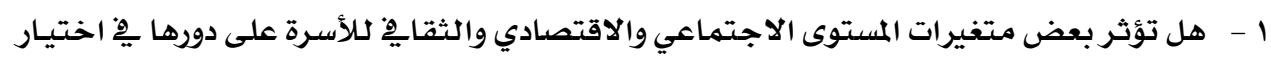
ألعاب أطفالها ؟ هول

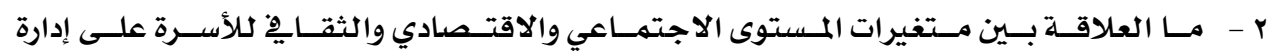
دخلها المالي؟

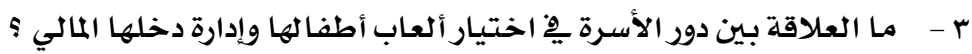

أهداف البحث:

$$
\text { يهدف البحث إلى التعرف على : }
$$

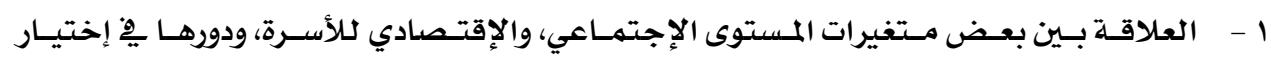
ألعاب أطفالها. r - - العلاقـة بـين بعـض مـتغيرات المستوى الإجتهـاعي ، والإقتـصادي للأسـرة، وأبعـاد إدارة الـدخل

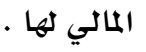
r - العلاقة بين دور الأسرة ِِِ إختيار ألعاب أطفا لها وإدارة الدخل المالي.

1 - إلقـاء الضوء على أهميـة اختيـار الأسـرة لألعـاب أطفا لها، ومواصفاتها، ونوعيتها، وكميتهـا

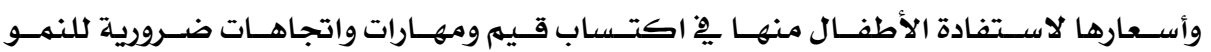

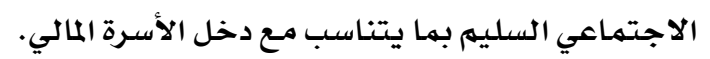

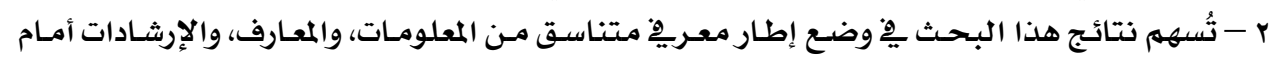

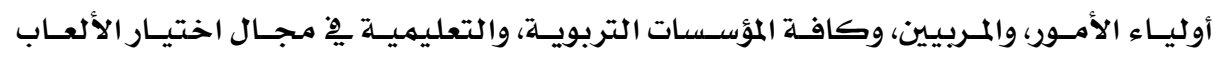

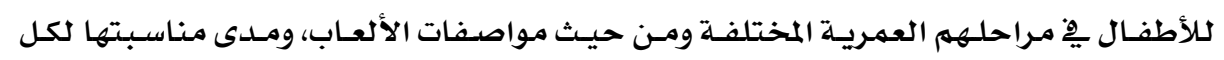

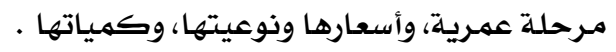

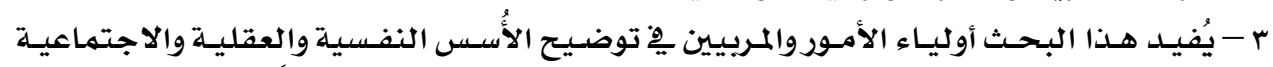

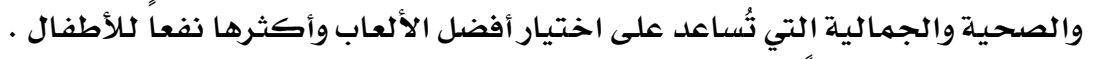

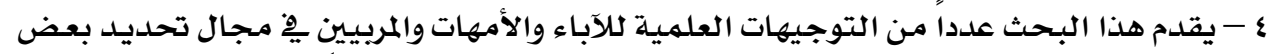

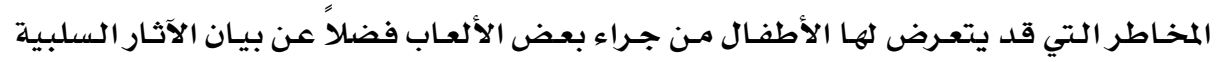

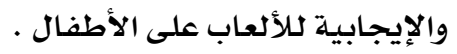




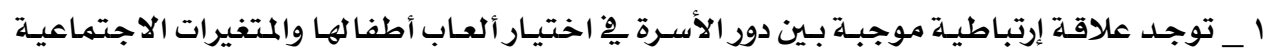

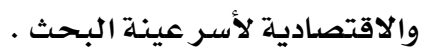

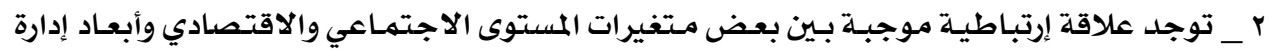

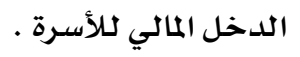

r _ توجد علاقة إرتباطية موجبلة بين دور الأسرة يِ اختيار ألعاب أطفا لها وأبعاد إدارة الدخل المالي.

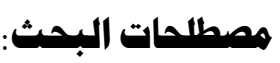

أولا : المصطلحات العلمية:

(The Role of the Family ) دور الأسرة : (T)

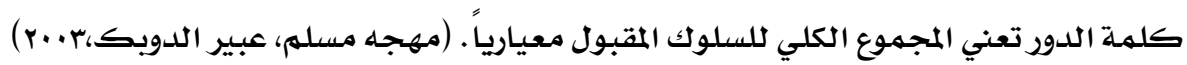

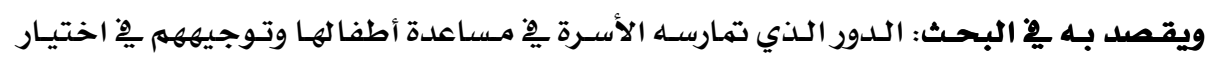

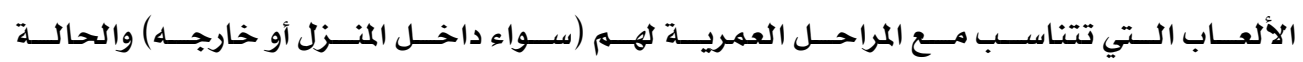

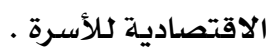

اللعب ( play ( ) ( )

ويعرف Good (1980) اللعب بأنه نشاط هـادف تعليمسي ضـروري للطفل يكتسب مـن خلالهـ

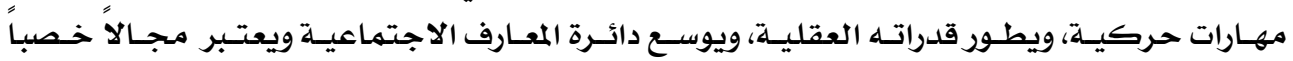

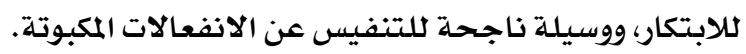

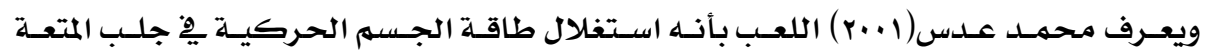

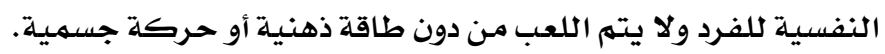

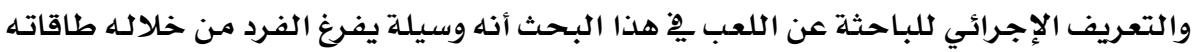

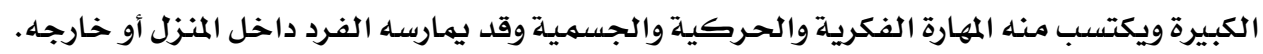

إدارة الدخل المالي (Management Financial income)

هي عملية توزيع الدخل الكلي للأسرة خاصدة النقد المتوفر، بما يحقق أهداف الأسـرة الرئيسية

$$
\text { والفرعية ـ (وفاء شلبي، 1991) }
$$

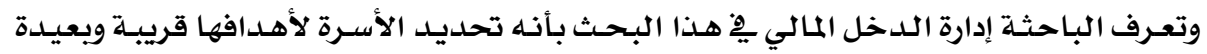

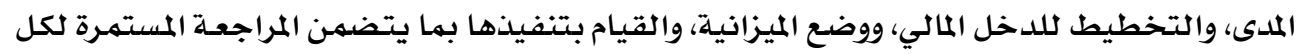

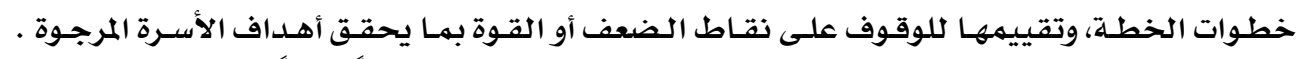

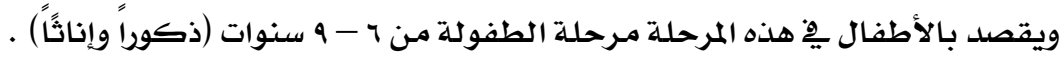




\section{الأسلوب البحثي للارواسة :}

\section{اـمنهج البحث::}

يتبع البحث المنهج الوصفي التحليلي الذي يعتمدل على دراسة الظاهرة ، ويهتم بوصفها وصفا

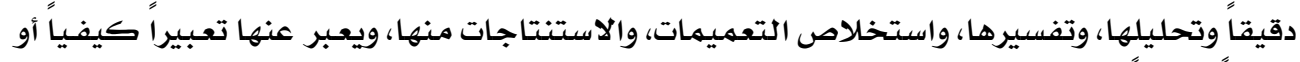

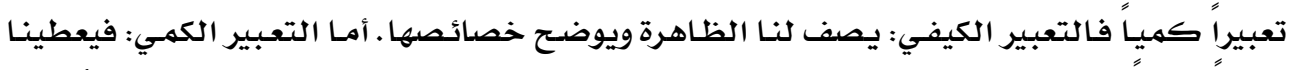

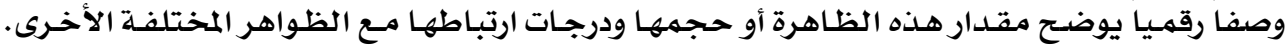

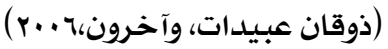

$$
\begin{aligned}
& \text { r ع عينة البحث: }
\end{aligned}
$$

عينة قصديه تشتمل على ·. . أسرة سعودية من مستويات اقتصادية، واجتماعية مختلفة لديها

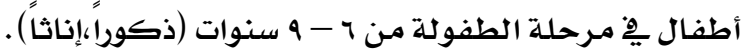

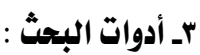

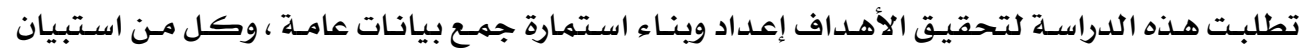

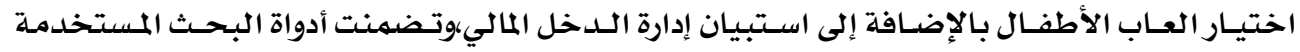
مايلي:

$$
\begin{aligned}
& \text { 1 _ البيانات العامـة للأسرة ( المستوى الاجتماعي والاقتصادي ). } \\
& \text { r _ بور الأسرة يِّ اختيار ألعاب الأطفال. } \\
& \text { rـ إدارة الدخل المالي. }
\end{aligned}
$$

أولاً : استمارة البيانات العامة لكلأسرة : إدارة الدخل

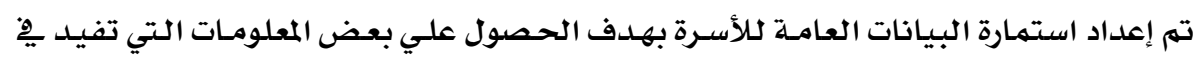

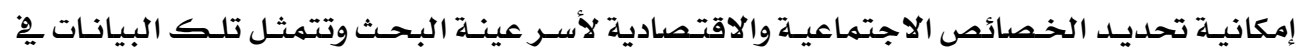

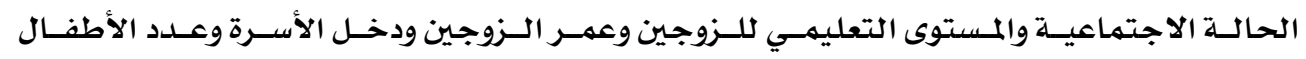

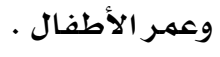

ثانيا : استبيان دور الأسرة فِ اختيار ألعاب أطفالها : وقاب

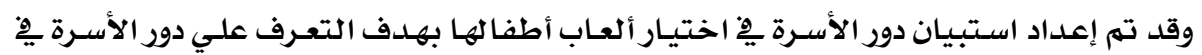

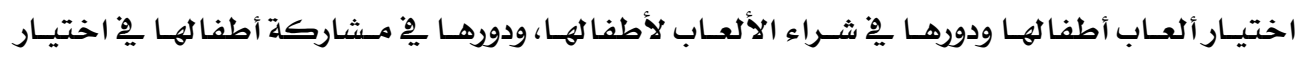

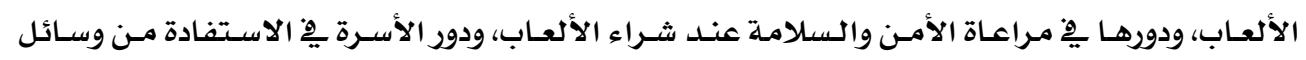

الإعلام مِ اختيار ألعاب أطفالها.

أعدت الباحثة (rv) عبـارة لقياس أثر وانعكاس دور الأسـرة يِّاخ اختيـار ألعـاب أطفا لها علسي إدارة

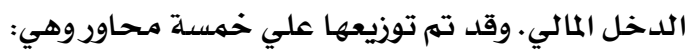


المحور الأول : دور الأسرة في اختيار الألعاب :

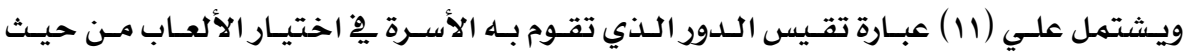

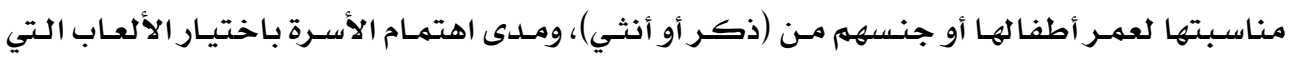

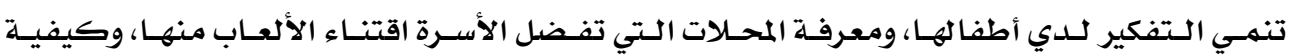

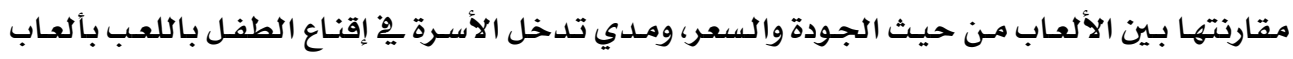
معينة، وكيفية الكشف عن العيوب يِّ الألعاب. المحور الثاني : دور الأسرة في شراء الألعاب :

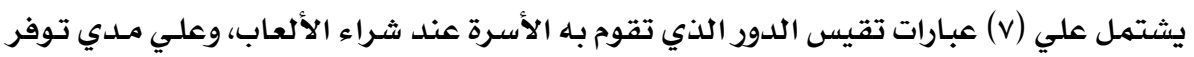

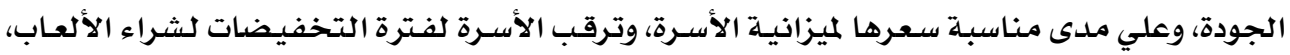

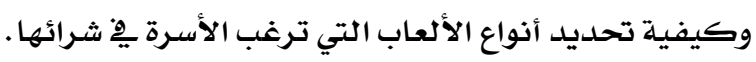
المحور الثالث : دور الأسرة في مشاركة أطفالها عند اختيار الأليار الألعاب :

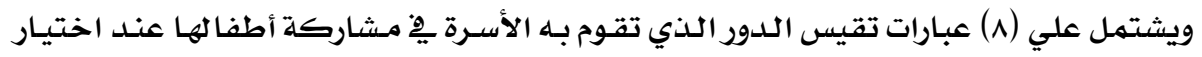

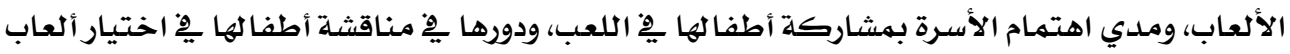

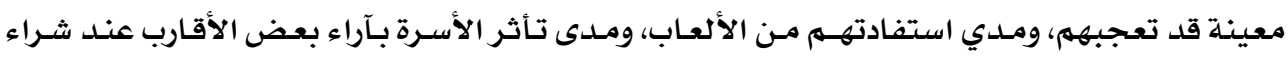
الألعاب. المحور الرابع : دور الأسرة في مراعاة الأمن والسلامة عند شراء الألعاب :

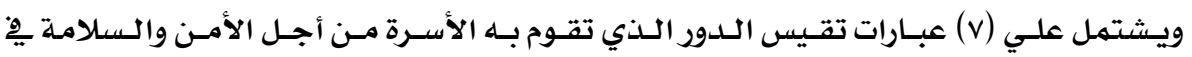

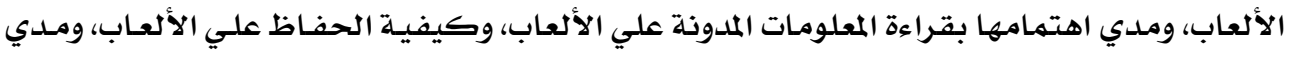

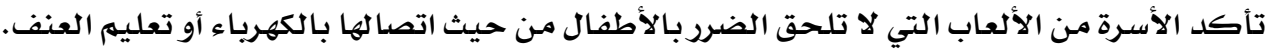
المحور الخامس : دور الأسرة في الاستفادة من وسائل الإعلام في اختيار ألعاب أطفالها :

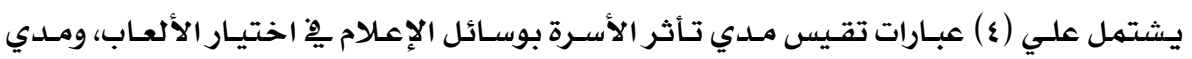

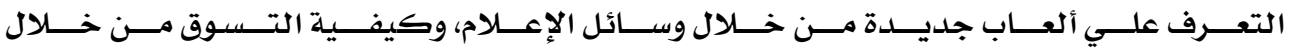
الإعلانات التلفزيونية. ثالثا: بناء استبيان إدارة الدخل المالي : ألماتي

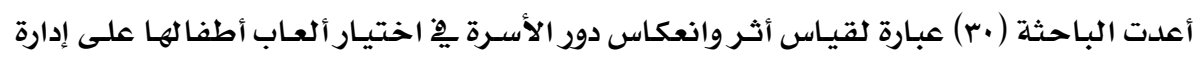

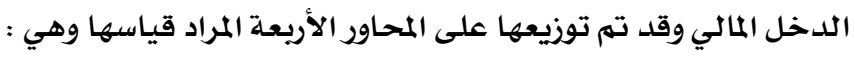

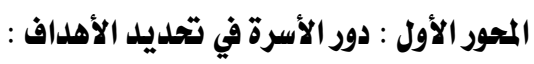
يشتمل على (v) عبارات تقيس الدور الذي تقوم به الأسـرة من تحديد احتياجـات أفراد الأسـرة،

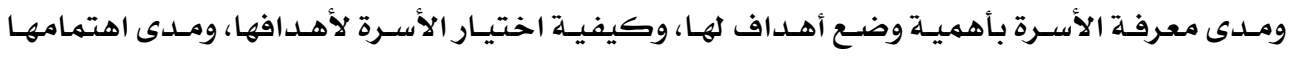

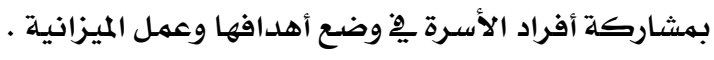


يشتمل على (ه) عبارات تقيس الدور الذي تقوم بـه الأسـرة ِِّ تخطيط دخلها مـن حيث وضـع

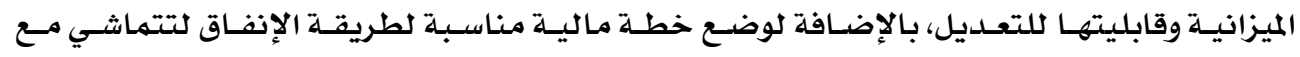

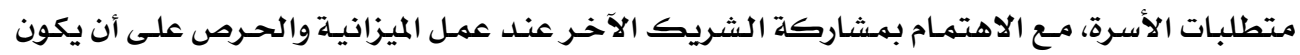

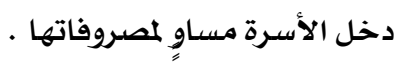

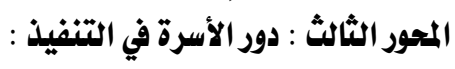
ويشتهل على (^) عبارات تقيس الدور الذي تقوم به الأسرة ِِّ طريقة تنفيـذ إدارة دخلها المالي

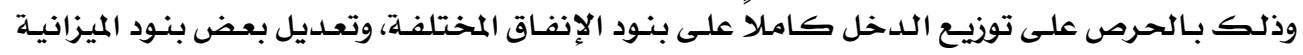

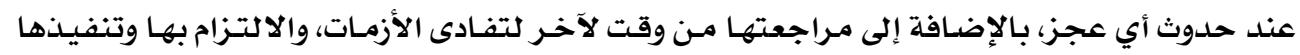

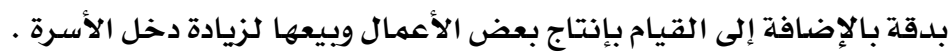

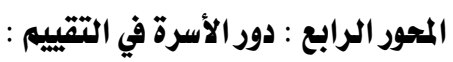

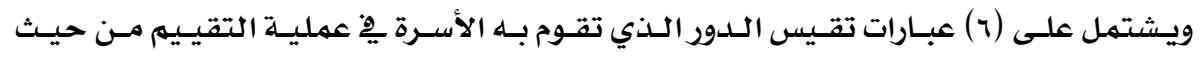

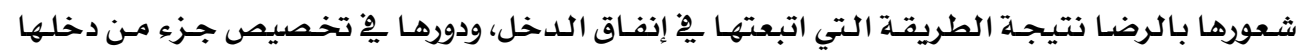

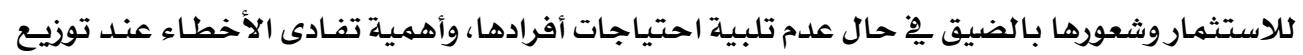

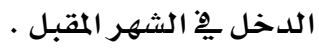

\section{صدق استبيان دور الأسرة يِ اختيار ألعاب أطفالها :}

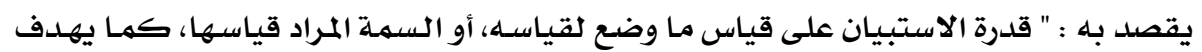

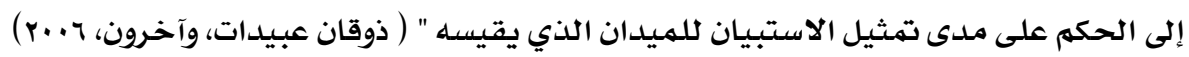

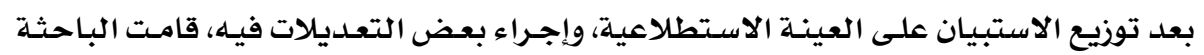

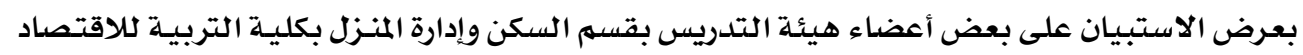

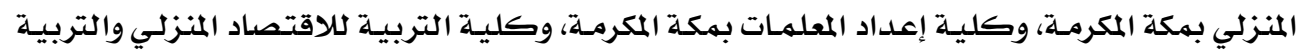

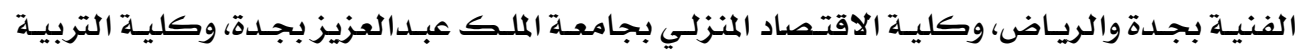

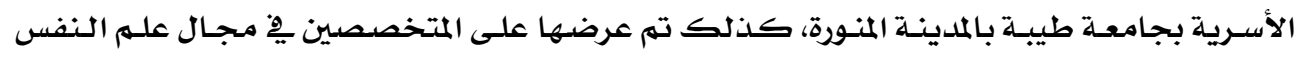

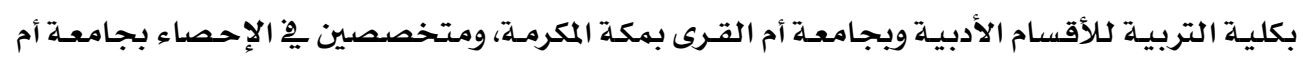

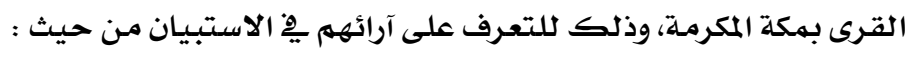

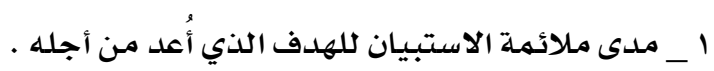

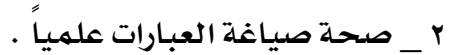

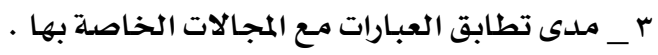
ثبات استبيان دور الأسرة فِ اختيار ألعاب أطفالها : ويقصد بثبات الاسـتبيان هـو " الاختبـار الذي يعطي نتائج متقاريـة أو النتائج نفسها ذا طبـق

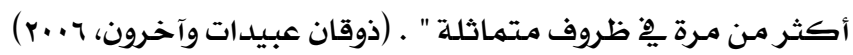




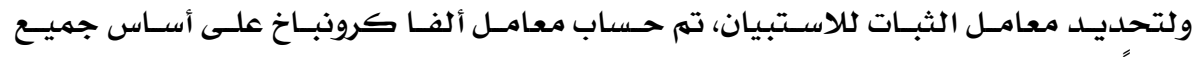

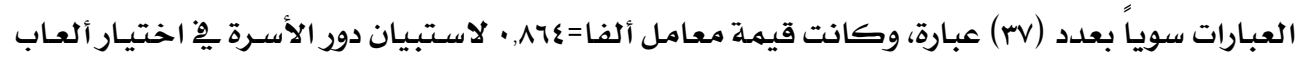

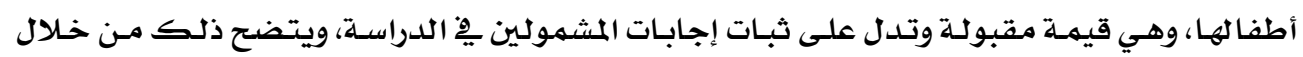

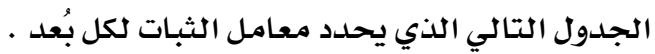

جدول (1) قيم معاملات الثبات لمحاور استبيان دور الأسرة يِ اختيار ألعاب أطفالها

\begin{tabular}{|c|c|c|}
\hline معامل الثبـات & علد العبارات & المحســـور \\
\hline •, 7 ro & 11 & الاختيـــار \\
\hline •, १४६ & $\checkmark$ & الشــــراء \\
\hline$\cdot, \mathrm{v} \leqslant 0$ & $\Lambda$ & الشاركـــة \\
\hline$\cdot, 7 r 1$ & $\checkmark$ & الأمن والسلامة \\
\hline •, \&AT & $\varepsilon$ & وسائل الإعلام \\
\hline$\cdot, \wedge \uparrow \xi$ & rr & اختيار الألعاب ككل \\
\hline
\end{tabular}

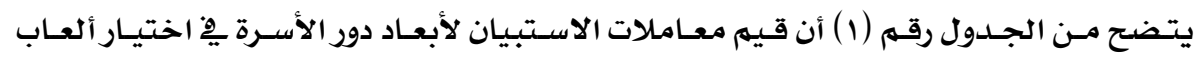

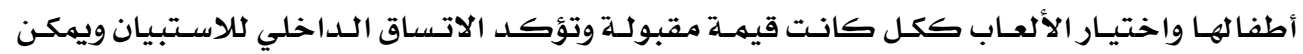

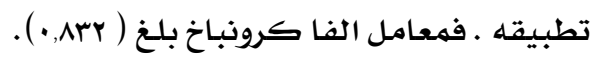
صدق استبيان إدارة الدخل المالي : بعد توزيـع الاستبيان على العينـة الاستطلاعية، وإجـراء بعض العض التعـديلات فيـه، قامـت البـاحثـة

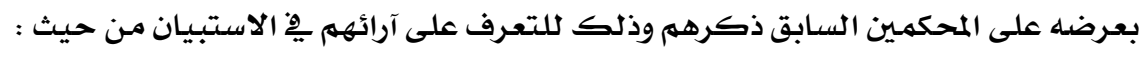

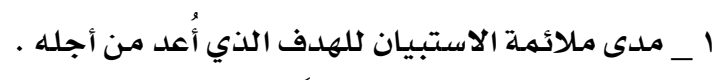
r _ صححة صياغة العبارات علمياً.

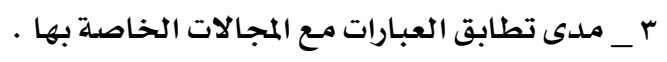
ثبات استبيان إدارة الدخل المالي : تحديد معامل الثبات للاستبيان، تم حسـاب معامل ألفـا كرونبـاخ على أسـاس جميـع العبـارات

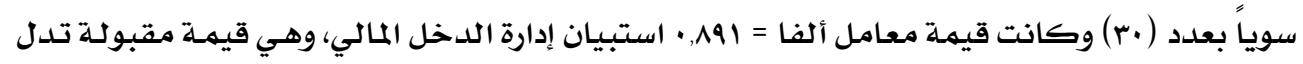

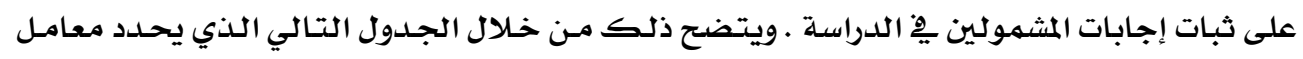

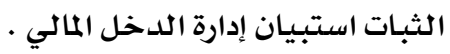




\begin{tabular}{|c|c|c|}
\hline معامل الثبـات & عدد العبارات & الأبعـــــاد \\
\hline •, Orr & $\checkmark$ & تحديد الأهداف \\
\hline$\cdot, \wedge \leqslant 1$ & 9 & التخطيط \\
\hline •, Trr & $\Lambda$ & التنفيـــذ \\
\hline •,Orl & 7 & التقيـيـيه \\
\hline$\cdot, \wedge 91$ & r. & الدخل المالي ككل \\
\hline
\end{tabular}

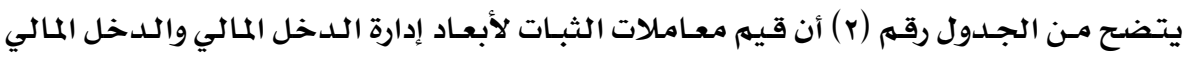

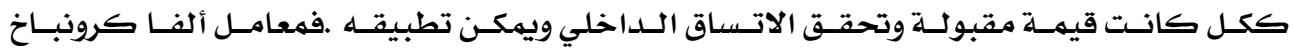

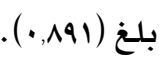
ع- التطبيق الميداني على عينة البحث:

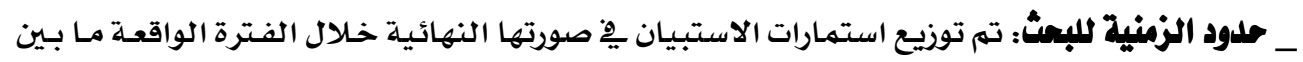

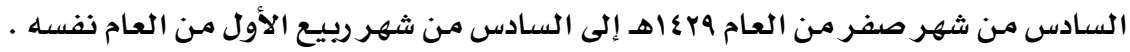

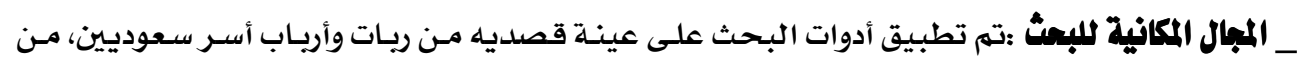

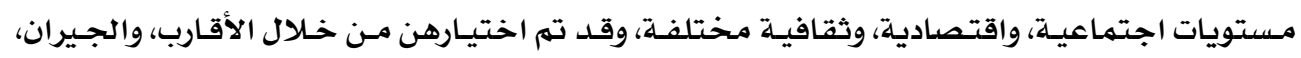

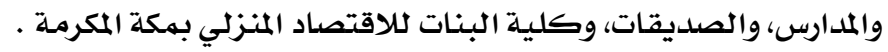
أولا : النتائج الوصفية الخاصة بالبيانات العامة للأسرة :

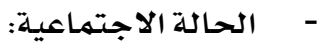

جدول (r) توزيع أفراد العينة تبعا للحالة الاجتماعية ن=...

\begin{tabular}{|c|c|c|}
\hline النسبة المئوية & العسد & الحالة الاجتماعية \\
\hline $9 r, 0$ & IAV & متزوجــون \\
\hline 0 & 1. & مطلقـون \\
\hline 1,0 & $r$ & أرامـل \\
\hline$\%$ & r.. & المجمهـوع \\
\hline
\end{tabular}

- يتضـح مـن الجـدول (r) أن أعلى نسبـة لعينـة البحـث كـانوا مـن المتزوجين حيـث بلغـت نسبتهم

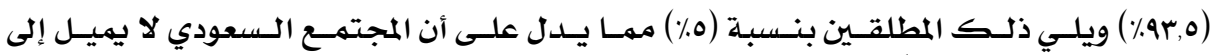

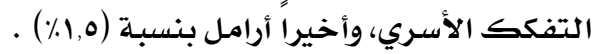


جدول (ع) توزيع أفراد عينة البحث تبعاً لعمر الزوجين ن = . F

\begin{tabular}{|c|c|c|c|c|}
\hline \multicolumn{2}{|c|}{ الـزوجة } & \multicolumn{2}{|c|}{ الـزوج } & \multirow{2}{*}{ فئة العمر للزوجين } \\
\hline النسبة المئوية & 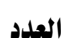 & النسبة المئوية & العلدد العد & \\
\hline$r \xi, 0$ & $\varepsilon 9$ & 0 & 1. & أقل من •r سنة \\
\hline$\xi \wedge$ & 97 & $\leqslant 9$ & 94 & من •r سنة لأقل من •؛ سنة \\
\hline rq & or & mq & vr & من •عسنة لأقل من •هسنة \\
\hline 1,0 & $r$ & $\Lambda, 0$ & iv & مز •مسنة لأقل من •7سنة \\
\hline - & - & 1,0 & $r$ & من • بسنة فأكثر \\
\hline$\%$ & r.. & $\%$ & r.. & المجمسوع \\
\hline
\end{tabular}

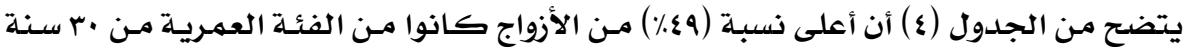

لأقل من •عسنـة واقل نسبـة ( 1,0 ٪) من الأزواج كانوا مـن الفئسة العمريـة •7 سنـة فأكثر، أمـا الزوجـات

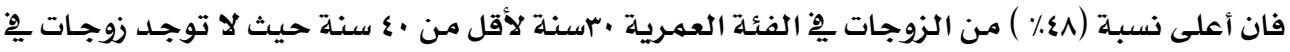
الفئة العمـريـة ·7 سنـة فأكثر. _ المستوى التعليمي : جدول (0) توزيـع أفراد عينة البحث تبعاً للمستوى التعليمي للزوجين ن = .. r

\begin{tabular}{|c|c|c|c|c|}
\hline \multicolumn{2}{|c|}{ الـزوجة } & \multicolumn{2}{|c|}{ الـزوج } & \multirow{2}{*}{ لمستوى التعليمي للزوجين } \\
\hline النسبة المئوية & العدد & النسبة المئوية & العدد & \\
\hline$\cdot, 0$ & 1 & $r$ & $\varepsilon$ & أمي (لا يترأ ولا يكتب) \\
\hline 1,0 & $r$ & 1,0 & $r$ & يقـرأ ويكتب \\
\hline r & $\varepsilon$ & $r, 0$ & v & الابتدائـــــية \\
\hline 11 & rr & $\wedge, 0$ & iv & المتوســــة \\
\hline $1 r, 0$ & rv & rI & $\xi r$ & الثانوية وما يعادلها \\
\hline ir & rz & ir & rq & دبلـــــوم \\
\hline $0 \xi$ & 1,1 & \&1 & Ar & الجامعــــة \\
\hline$\xi, 0$ & 9 & 7 & ir & ماجســـتير \\
\hline 1 & $r$ & $r, 0$ & $\checkmark$ & دكتــوراه \\
\hline$\% 1 \ldots$ & r... & $\% 1 \cdots$ & r.. & المجمـوع \\
\hline
\end{tabular}




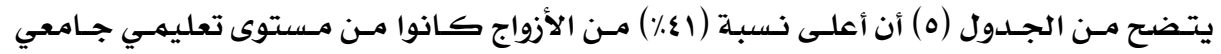

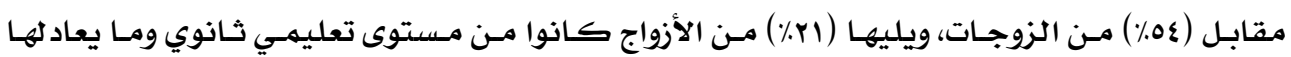

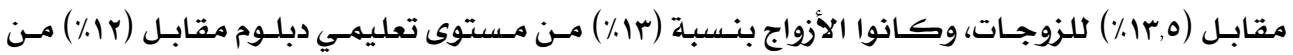

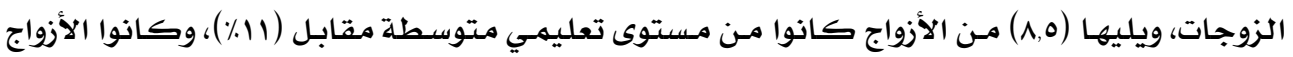

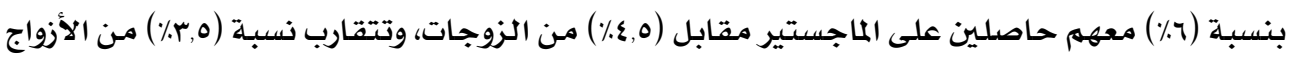

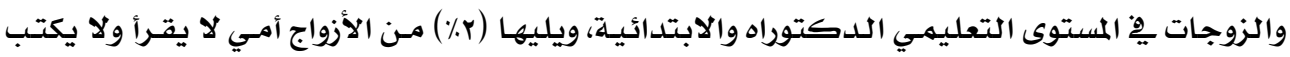

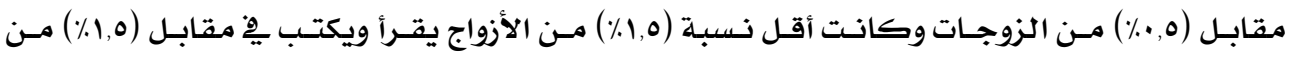

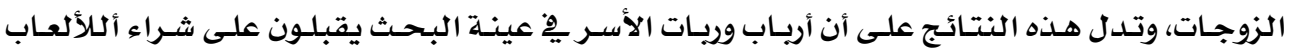

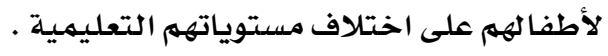

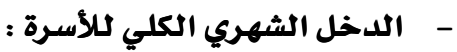
جدول (ج) توزيع أفراد عينة البحث تبعاً لمقدار الدخل الشهري الكلي للأسرة ن=...

\begin{tabular}{|c|c|c|}
\hline النسبة المئوية & 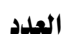 & مقدار اللدخل الشهري الكلي للأسرة بالريال السعودي \\
\hline 11 & rr & 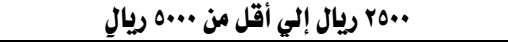 \\
\hline ri,o & $\varepsilon r$ & 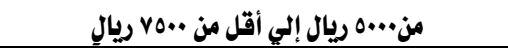 \\
\hline ro & 0. & من.•v ريال إلي أقل من •...ا ريالِ \\
\hline$\varepsilon r, 0$ & 10 & 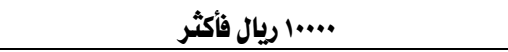 \\
\hline$\%$ & r.. & المجمـوع \\
\hline
\end{tabular}

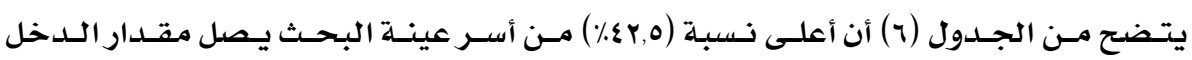

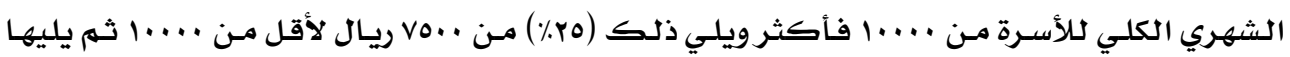

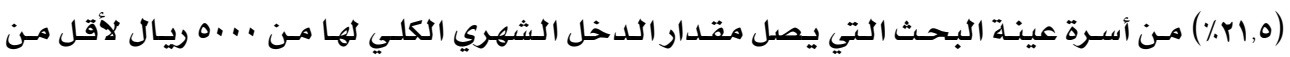

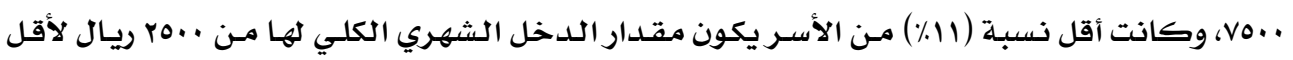
من .... من ريال.

ـ ثانيا :النتائج الوصفية الخاصة بيبانات الأطفار : مبال _ عدد الأطفال ــ ـ أسر عينة البحث : 


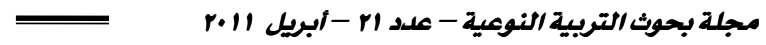

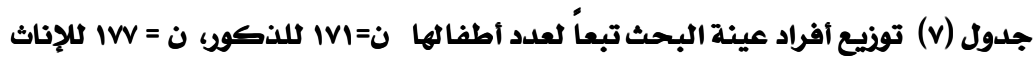

\begin{tabular}{|c|c|c|c|c|}
\hline \multicolumn{2}{|c|}{ الإنـاث } & \multicolumn{2}{|c|}{ الذكــور } & \multirow{2}{*}{ عدد الأطفال في الأسرة } \\
\hline النسبة المئوية & العدد & النسبة المئوية & العدد & \\
\hline$r r, r$ & $\Delta q$ & ro, r & \&r & واحد (1) \\
\hline$r \xi, q$ & $\xi \varepsilon$ & $r \varepsilon, 0$ & $\Delta 9$ & اثنين (r) \\
\hline$r r, Y$ & $\varepsilon r$ & $r 0,1$ & ¿r & ثلاثة (r) \\
\hline 11,1 & rr & $10, r$ & rq & أربعة (צ) فأكثر \\
\hline$\% 1 \cdots$ & ivr & $\% 1+$ & $|r|$ & المجمـوع \\
\hline
\end{tabular}

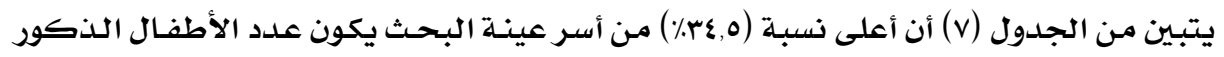

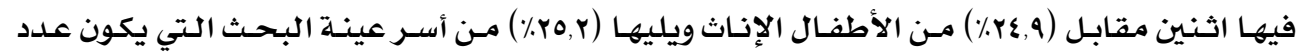

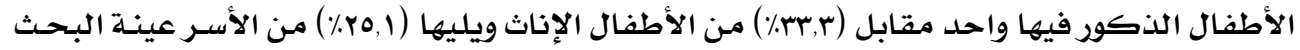

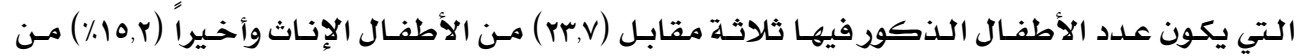

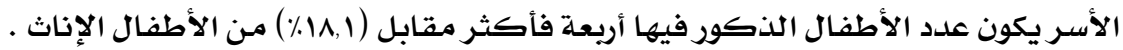

9

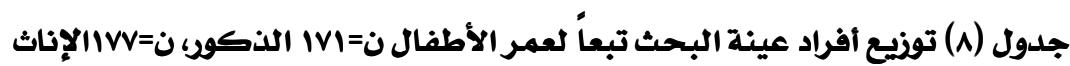

\begin{tabular}{|c|c|c|c|c|}
\hline \multicolumn{2}{|c|}{ الإنـاث } & \multicolumn{2}{|c|}{ الذكـور } & \multirow{2}{*}{ عمر الأطفال } \\
\hline النسبة المئوية & العدد & النسبة المئوية & 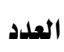 & \\
\hline$r, q$ & 07 & $r, \cdot 0$ & mq & أقل من 1 سنوات \\
\hline $\mathrm{rq}, \mathrm{A}$ & 70 & $0 ., \mathrm{rq}$ & $\wedge 9$ & من 1 سنوات لأقل من 9 سنوات \\
\hline $\mathrm{rI,Y}$ & 70 & $r \wedge, 7 \uparrow$ & $\leqslant 9$ & من ه سنوات فأكثر \\
\hline$\%$ & irr & $\%$ & $|v|$ & المجمـوع \\
\hline
\end{tabular}

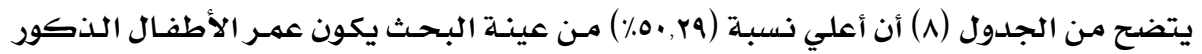

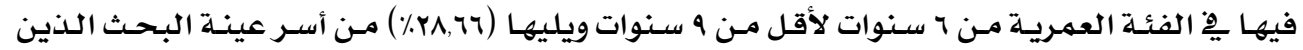

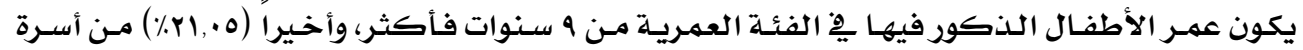

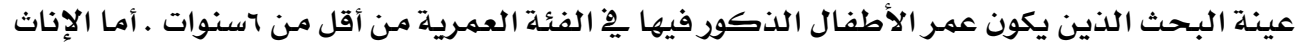

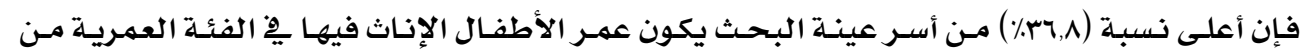

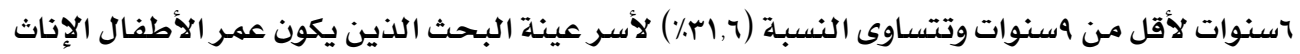

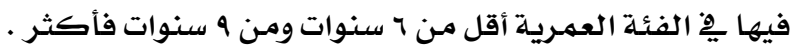


ثالثا :النتائج في ضوء فروض البحث:

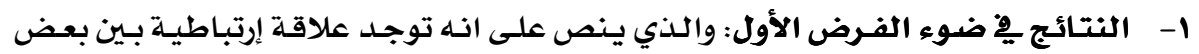

متغيرات المستوى الاجتماعي والاقتصادي ومحاور اختيار العاب الأطفال.

\begin{tabular}{|c|c|c|c|c|c|c|c|c|c|c|c|c|c|c|c|c|c|c|c|c|c|c|}
\hline $\begin{array}{l}\overline{3} \\
: 3 \\
\overline{3}\end{array}$ & 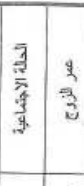 & $\begin{array}{lll}2 & 1 \\
3 & 3 \\
3\end{array}$ & $\begin{array}{l}\frac{3}{3} \\
\frac{3}{3} \\
\frac{3}{3} \\
\frac{3}{3} \\
3 \\
3\end{array}$ & $\begin{array}{l}\frac{1}{3} \\
\frac{9}{3} \\
3 \\
3\end{array}$ & 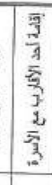 & $\frac{1}{3}$ & $\begin{array}{l}\frac{1}{3} \\
\frac{1}{62} \\
\frac{3}{3} \\
\frac{3}{3} \\
7\end{array}$ & $\frac{3}{3}$ & 亭 & 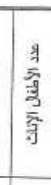 & 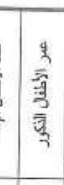 & 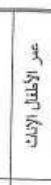 & $\frac{3}{3}$ & $\frac{3}{3}$ & 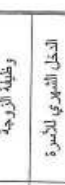 & & 忞 & 可 & $\frac{7}{y}$ & $\begin{array}{l}\sqrt{3} \\
3 \\
3 \\
3\end{array}$ & $\begin{array}{ll}\frac{3}{3} \\
\frac{3}{3} \\
\frac{3}{2}\end{array}$ & $\begin{array}{l}\frac{1}{3} \\
\frac{3}{3} \\
\text { y }\end{array}$ \\
\hline 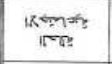 & & 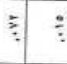 & $\vdots$ & & $: 5$ & 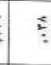 & $\bar{\partial}$ & $\bar{\vdots}$ & $\bar{\square}$ & 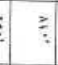 & $\bar{a}$ & & $\because$. & & $\equiv$ & $=$ & &. & 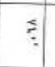 & 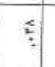 & 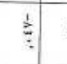 & $=$ \\
\hline orerpera & & : : & 5 & $:$ & 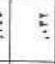 & $:$ & $\cdot$ & $=:$ & $: 5$ & $:$ & $:$ & $:$ & $=:=$ & & $:$ & & 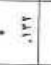 & & 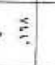 & $\vdots$ & . & \\
\hline or prerey & & & $\stackrel{9}{\circ}$ & $\stackrel{5}{\square}$ & & $: \vdots$ & $\cdot 5$ & $: \div$ & .5 & $:=$ & $\cdot 5$ & $:$ & $=:$ & & $\overline{:}:$ & $\vdots$ & $\dddot{3}$ & $\vdots:$ & $=$ & 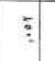 & 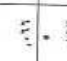 & $=$ \\
\hline mang & & & & $: \div$ & & 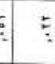 & $:$ & $\doteqdot$ & $\because$ & $=$ & $\vdots$ & & 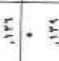 & & & 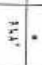 & 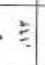 & : & 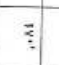 & 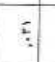 & 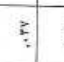 & $\vdots$ \\
\hline 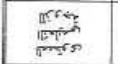 & & & & & & $:=$ & $:=$ & $:=$ & $\cdot$ & $:=$ & $=$. & & $:$ & & & 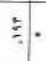 & $\stackrel{s}{s}$ & $5:$ & : & 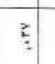 & & 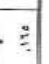 \\
\hline 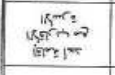 & & & & & & ఏ & & $\cdot ?$ & $\bar{Z}$ & & $\vdots$ & & 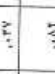 & & 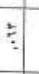 & 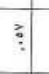 & 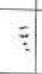 & ؛ & $?$ & $\vdots$ & ¿ & 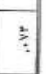 \\
\hline Tempits: & & & & & & & 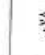 & 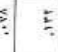 & $:$ & $\cdot$ & 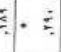 & & 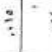 & $\ddot{a}:=$ & & 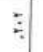 & 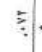 & . & . & : & है. & 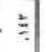 \\
\hline mentron & & & & & & & & & $:$ & & . & & & & 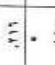 & 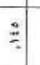 & $\vdots$ & 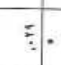 &. & $\because:$ & & 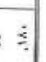 \\
\hline 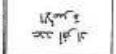 & & & & & & & & & : & $:=$ & & $:$ & & . & $\cong$. & $\equiv$ & $\vdots$ & $\vdots$ & $\bar{\vdots}$ & : & 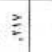 & 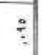 \\
\hline 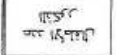 & & & & & & & & & & 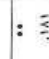 & & $:$ & 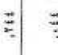 & 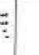 & ڤ. & : & $\because$. & . & & 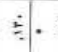 & & $=$ \\
\hline 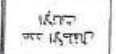 & & & & & & & & & & & & $:$ & . & & 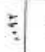 & 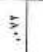 & . & - E: & 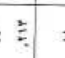 & $\doteqdot \cdot$ & & 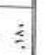 \\
\hline 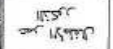 & & & & & & & & & & & & $:$ & $\vdots$ & & ○َ. & $\lesssim$ & 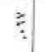 & : & $\frac{t}{a}$ & $\vdots$ & & 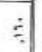 \\
\hline 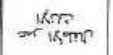 & & & & & & & & & & & & & $: \vdots$ & & 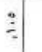 & 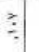 & & $\equiv$ & $\vdots$. & : & $::$ & \\
\hline 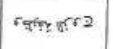 & & & & & & & & & & & & & & $::$ & & : & : & $\doteqdot$ & 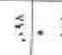 & . & $\equiv$. & $\vdots$ \\
\hline refoentrets & & & & & & & & & & & & & & & & & $\vdots:$ & $\equiv$. & : & 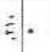 & $\vdots$ & 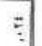 \\
\hline 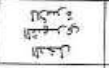 & & & & & & & & & & & & & & & & & $\equiv$. & & : : & & 气. & $\overline{1}$ \\
\hline 1אख? & & & & & & & & & & & & & & & & & & : & $=$ & : & $E:$ & \\
\hline$\| r_{0}$ & & & & & & & & & & & & & & & & & & & $:$ & & : & \\
\hline mins & & & & & & & & & & & & & & & & & & & & : & : & \\
\hline$\sqrt{r_{10 x}}=x$ & & & & & & & & & & & & & & & & & & & & & : & \\
\hline 120 & & & & & & & & & & & & & & & & & & & & & : & 先 \\
\hline 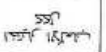 & & & & & & & & & & & & & & & & & & & & & & \\
\hline
\end{tabular}




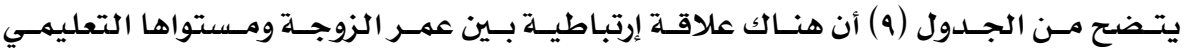

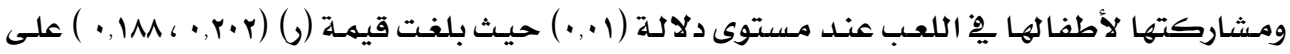

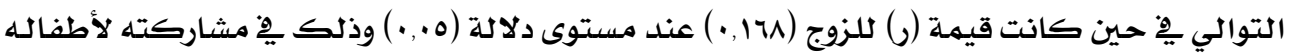

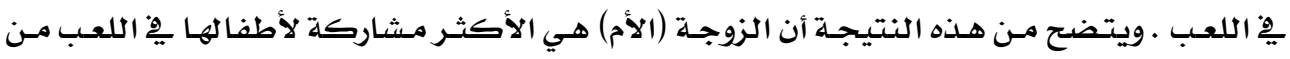

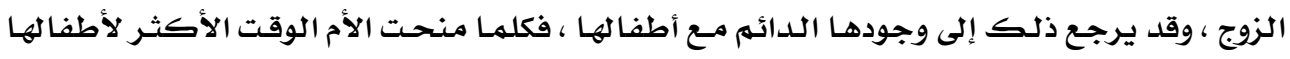

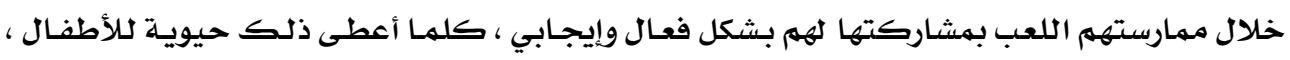

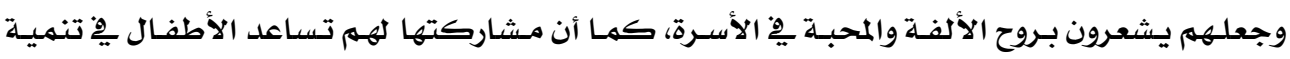

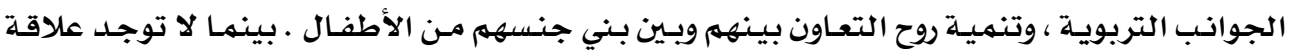

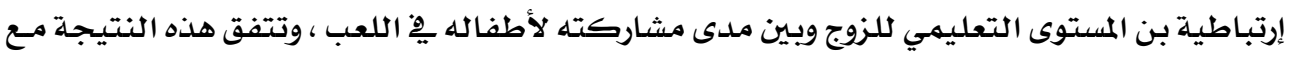

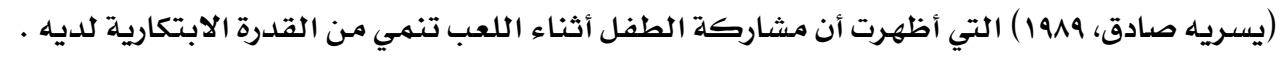

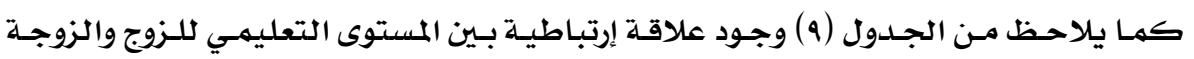

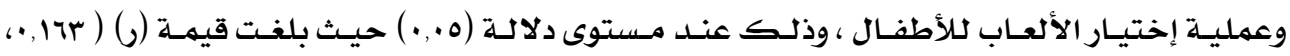

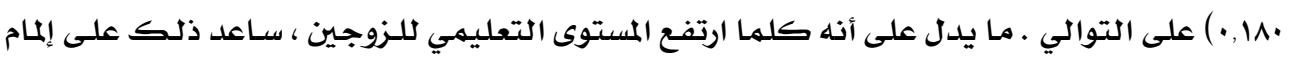

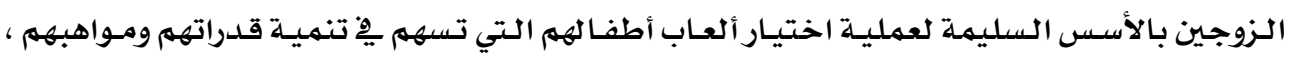

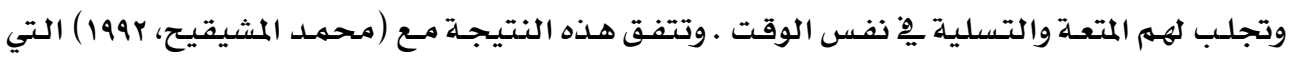

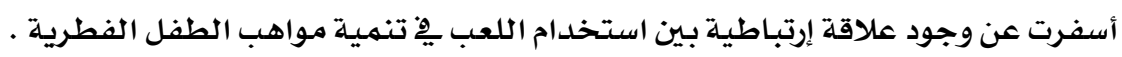

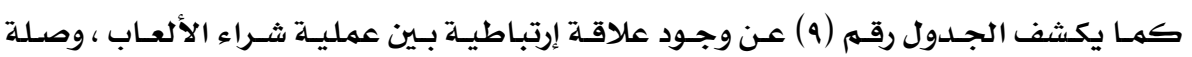

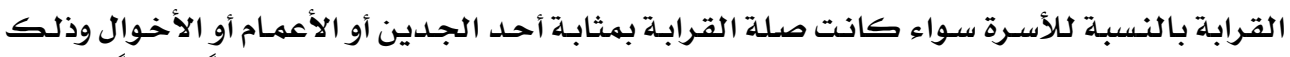

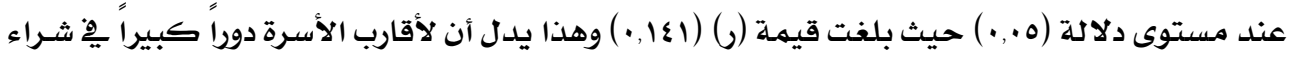

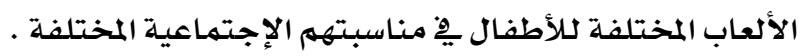

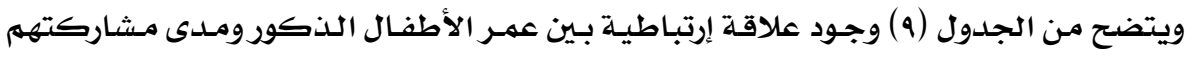

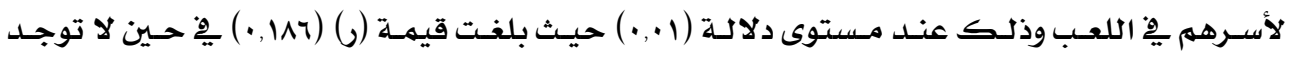

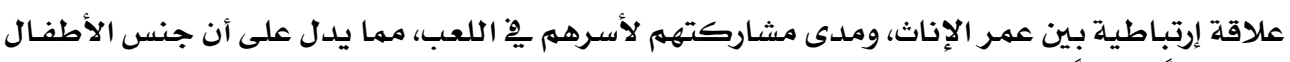

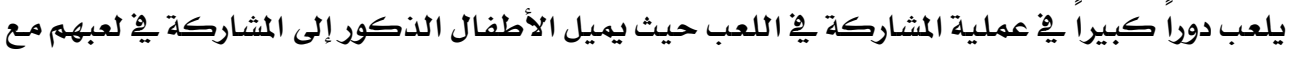

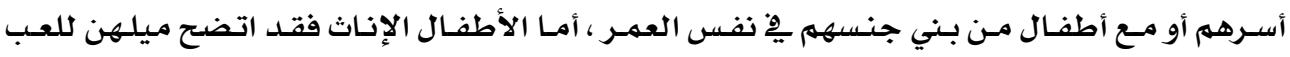

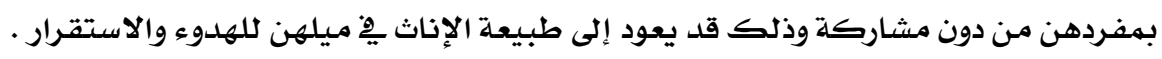

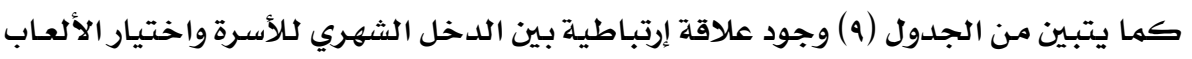

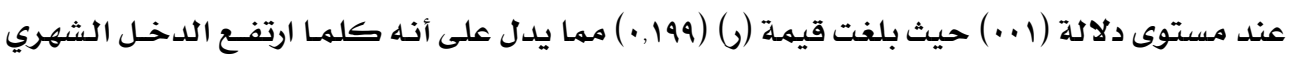

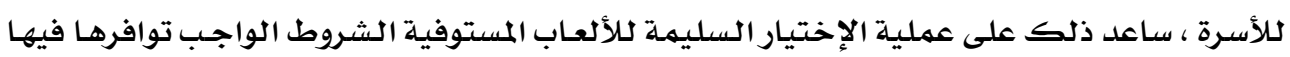

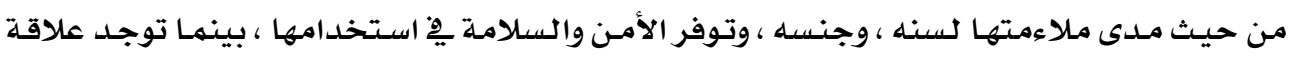

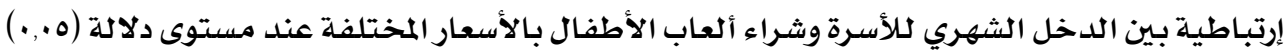




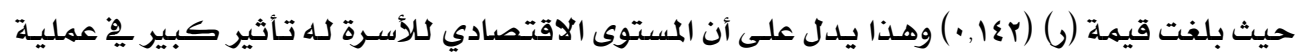

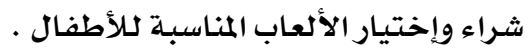

كما توجد علاقة إرتباطية بين بعض متغيرات المستوى الإجتمـاعي والاقتصادي ، ومجموع

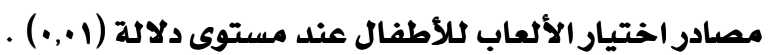

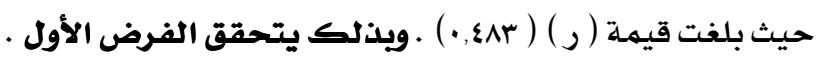

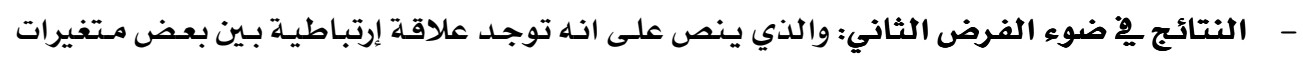

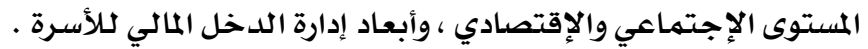

\begin{tabular}{|c|c|c|c|c|c|c|c|c|c|c|c|c|c|c|c|c|c|c|c|c|}
\hline $\begin{array}{l}\overline{3} \\
\frac{9}{3}\end{array}$ & $=$ & & $\begin{array}{l}\frac{1}{3} \\
\frac{1}{3} \\
\frac{3}{3} \\
3\end{array}$ & & $\begin{array}{l}\frac{3}{3} \\
\frac{3}{3} \\
\frac{3}{3} \\
\frac{2}{3} \\
3 \\
3\end{array}$ & $\frac{3}{3}$ & 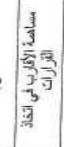 & $\begin{array}{l}3 \\
\frac{3}{3} \\
\frac{3}{3} \\
3 \\
3\end{array}$ & 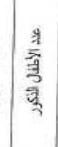 & 素 & 类 & 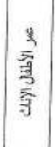 & 妻 & $\begin{array}{l}3 \\
3 \\
3\end{array}$ & $\begin{array}{l}\overline{3} \\
\overline{3} \\
3 \\
3\end{array}$ & 亳 & 可 & 再 & 烈竞 & $\begin{array}{l}\frac{x}{3} \\
\frac{3}{3} \\
3 \\
3 \\
3\end{array}$ \\
\hline verexixtent $\Rightarrow$ & & 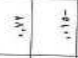 & & 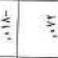 & $=\frac{1}{3}$ & & $:=$ & $\bar{\vdots}$ & $\vdots$ & 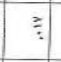 & $\Xi$ & &.$\equiv$ & 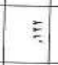 & 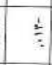 & 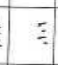 & ?ִ & $\fallingdotseq$ & $\equiv$ & $\fallingdotseq$ \\
\hline or orfa & & $:=$ & & $=$ & 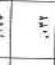 & &. & $=\dot{\epsilon}$ & $=\leqslant$ & $=:$ & $:$ & $=\frac{2}{7}:$ & $:=$ & & $: \equiv$ & $\vdots$ & 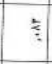 & 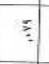 & $\bar{B}$ & 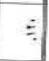 \\
\hline ore orrets & & & 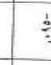 & 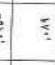 & $\bar{z}$ & 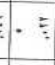 & $-\equiv$ & $=\frac{1}{3}$ & $\cdot E$ & $=\Sigma$. & . & $: \geq:$ & $:=$ & & $: \equiv$ & $\doteqdot$ & 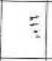 & $\fallingdotseq$. & . $\equiv$. &. \\
\hline ring & & & & $:=$ & $\bar{\vdots}$ & & $:=$ &.$\equiv$ & 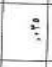 & $\equiv$ & $\equiv$. & . 5. &. & & $=F$ & $\dddot{\ddots}$ & 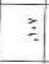 & $\vdots$ & & $\cdot \div$ \\
\hline mats & & & & & & $:=$ & $=\leqslant$ & $\fallingdotseq$ & $\cdot E$ & $=\leqq$. & $\cdot$ & $: \stackrel{2}{\because}:$ & $:=$ & $: \xi$ & $= \pm$ & 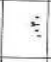 & $\vdots$ & . & $\vdots$. & 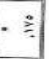 \\
\hline 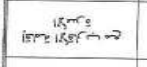 & & & & & & . $\cdot$ & 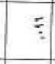 & - $\equiv$ & 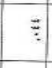 & $\vdots$ & $\vdots$ & 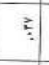 & $\vdots$ & $\because$ & 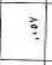 & $\because$ & 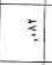 & $\vdots$. & 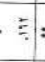 & $=$ \\
\hline Teterite & & & & & & & & $\cdot 5$ & $: \vdots$ & $: \vdots:$ & $\therefore$ & $\fallingdotseq$. & - & $: \equiv$ & $=$ & 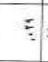 & $: \equiv$. & 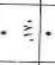 &. & - \\
\hline 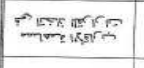 & & & & & & & & . & $:$ & . $=$. &. & . & . & $: \equiv$ &.$\triangleq$ &. &.$\equiv$ & $\fallingdotseq:$ & $=$. & $\cdot \equiv$ \\
\hline arifinisurs: & & & & & & & & & . $\equiv$. & -. & $\cdot 5:$ & $=\equiv$. & . &. & 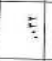 & $\vdots$ & & . & & $=$ \\
\hline $\begin{array}{l}\text { ansers } \\
\text { artistor }\end{array}$ & & & & & & & & & & . & . & $: \equiv:$ & $=$ & $\therefore$ & 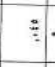 & & : & $\cdot \dot{=}:$ & : & $=$ \\
\hline 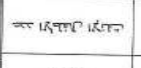 & & & & & & & & & & & $\cdot \equiv$ & $=\vdots$. & . & $=$ & . & $\equiv$ & $:=$ & $=$ & &. \\
\hline arsisere & & & & & & & & & & & & $=$. & - $=$ & $\equiv$. & . &.$\triangleq$ & & 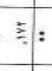 & $\equiv$. & 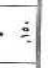 \\
\hline 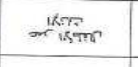 & & & & & & & & & & & & & $=$ & $=$ & $=1$. & $\cdot \pm$ & $\cdot=$ & $=$ & & $=$ \\
\hline 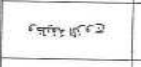 & & & & & & & & & & & & & & & $=$ & $:=$ & . & $=:$ & $E$. & $\cdot$. \\
\hline rtwe rerts & & & & & & & & & & & & & & & $:=$ & $=$ & $: \equiv$ & $=$ & & $=$ \\
\hline 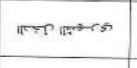 & & & & & & & & & & & & & & & & $: 5$. & - & $=$ & $=$ & $=$ \\
\hline I & & & & & & & & & & & & & & & & & & $=:$ & & $=0$ \\
\hline का नाय & & & & & & & & & & & & & & & & & & & & $=\mathrm{E}$ \\
\hline$y=\pi$ & & & & & & & & & & & & & & & & & & & & $=5$ \\
\hline 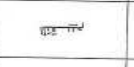 & & & & & & & & & & & & & & & & & & & & $=5$ \\
\hline 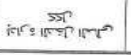 & & & & & & & & & & & & & & & & & & & & \\
\hline
\end{tabular}


يتضح من الجدول ( م ) عدم وجود علاقة إرتباطية بين عمر الزوج والزوجة والمستوى التعليمي

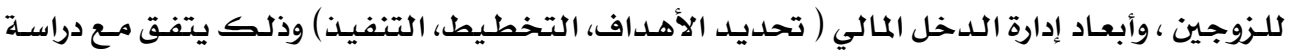

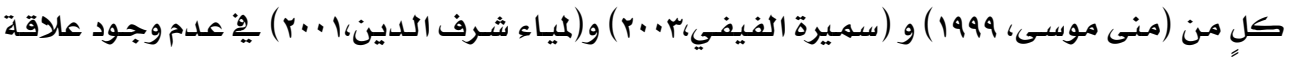

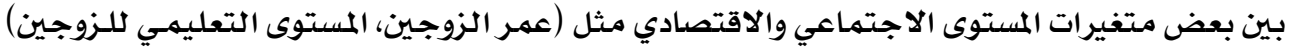

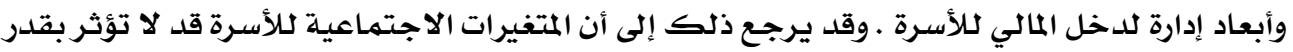

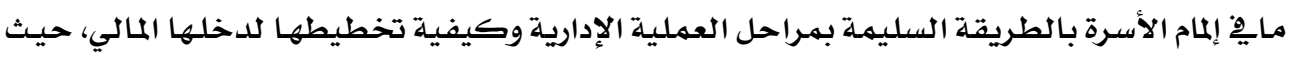

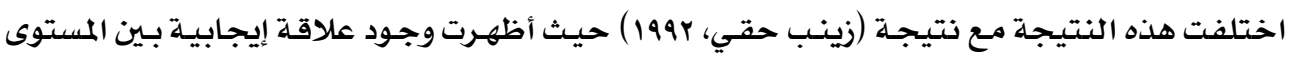

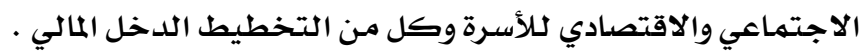

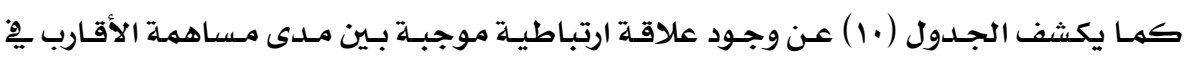

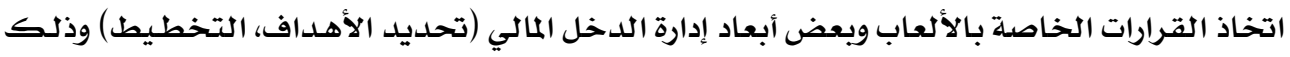

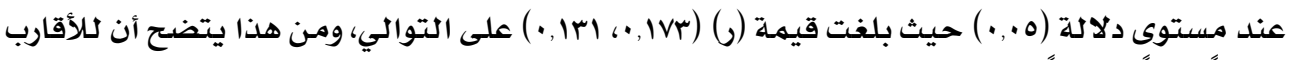

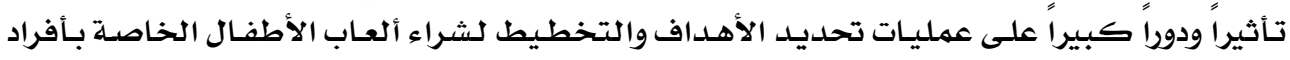

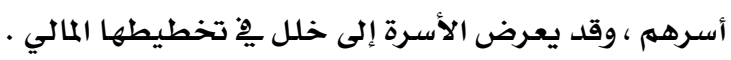

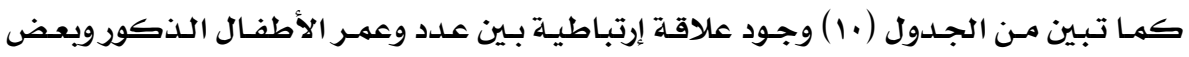

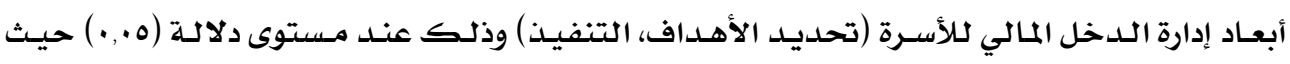

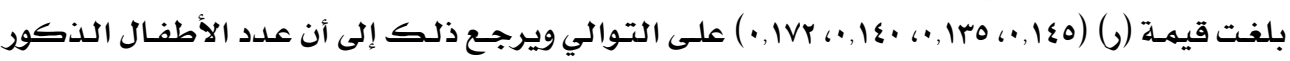

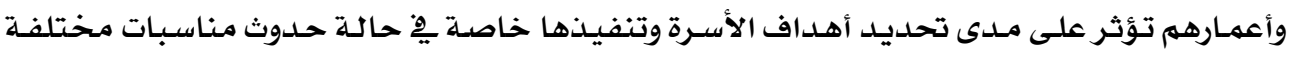

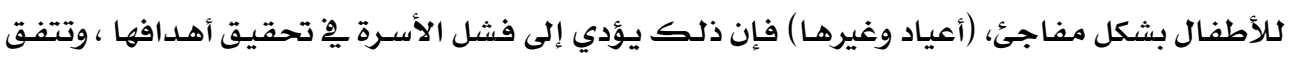

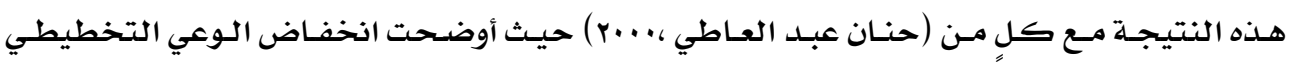

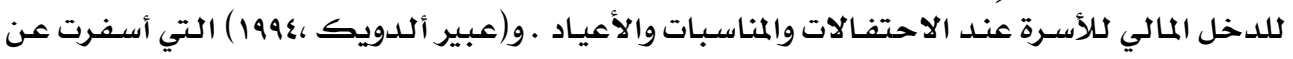

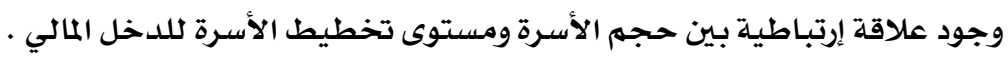

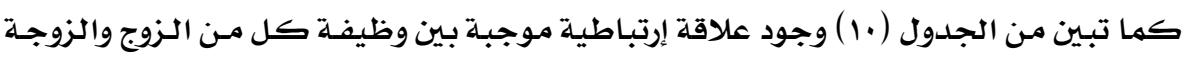

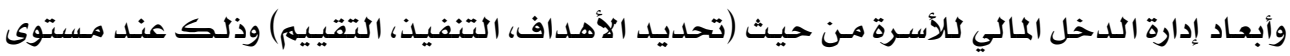

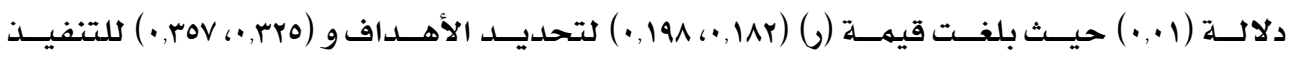

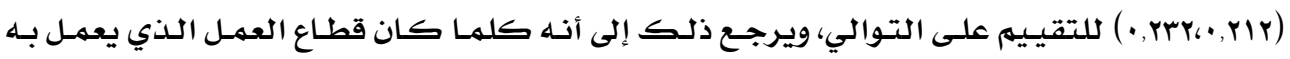

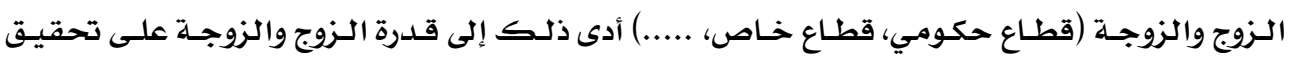

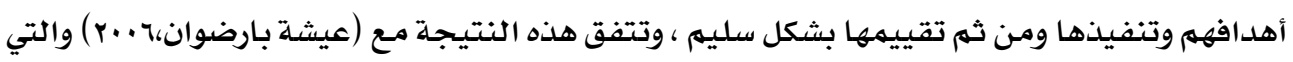

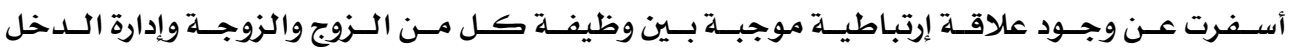
المالي لكلأسرة . المفرت

كهما اتضـح مـن الجـدول (rr) وجـود علاقة إرتباطيـة موجبـة بـين وظيفـة الزوجـة ، وأبعاد إدارة

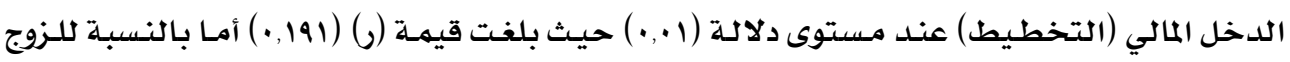

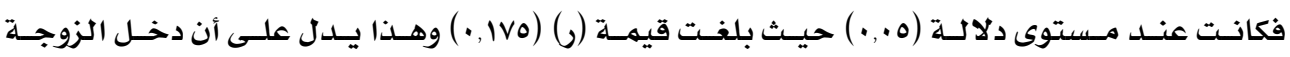




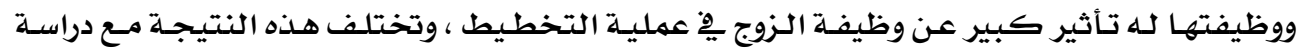

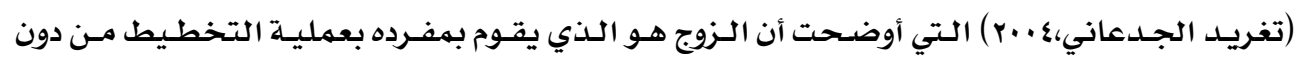

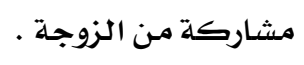

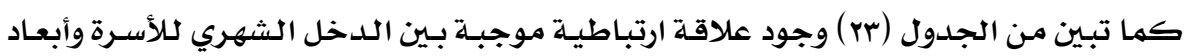

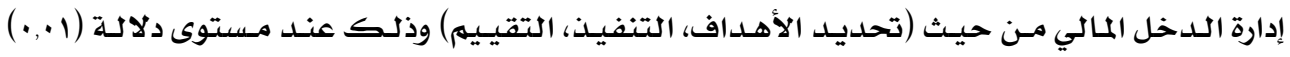

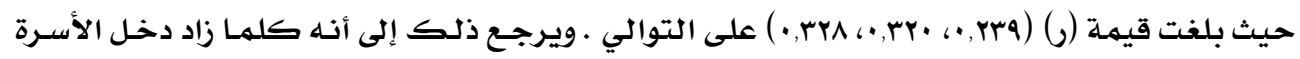

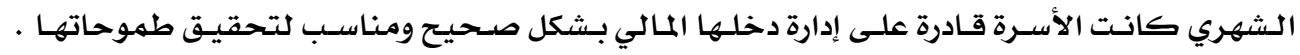
وتتفـق هـذه النتيجـة مـع كـلٍ مـن (Fanning, 1981) و (Ivan and Jerald,1987) و (أمـل

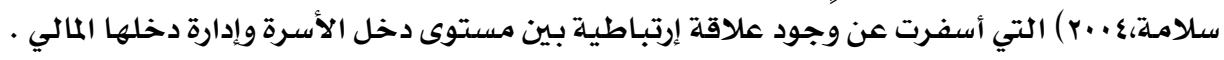

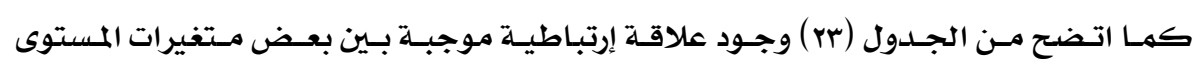

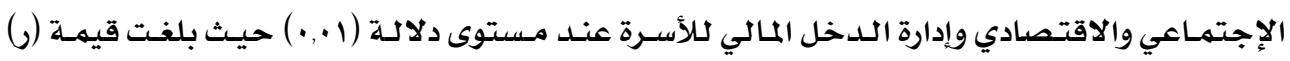

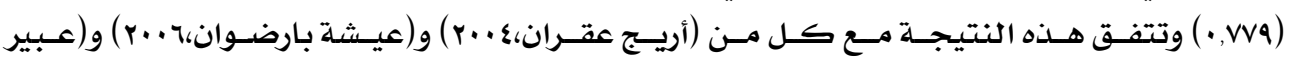

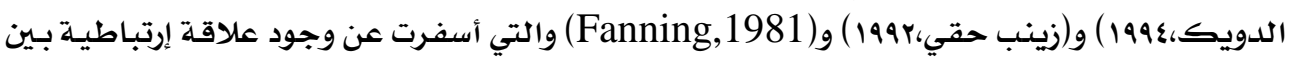

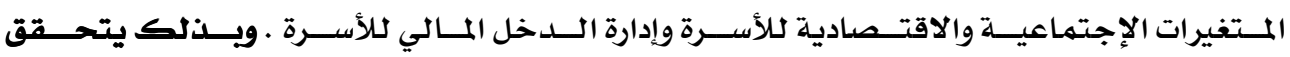
الفرض الثاني. النتائج هِ ضوء الفرض الثالث : و الذي ينص على توجد علاقـة إرتبـاطيـة موجبـة بـين اختيـار الأسـرة

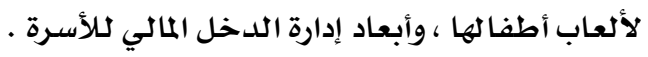




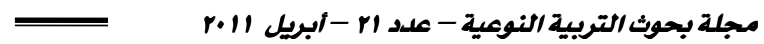

\begin{tabular}{|c|c|c|c|c|c|c|c|c|c|c|c|}
\hline $\begin{array}{l}\overline{3} \\
\vdots \overline{3} \\
\overline{7}\end{array}$ & $\begin{array}{l}\overline{2} \\
: 1 \\
7 \\
7\end{array}$ & $\frac{\sqrt{3}}{a}$ & $\frac{\bar{s}}{y}$ & 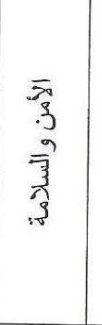 & $\begin{array}{l}\frac{3}{3} \\
\frac{3}{3} \\
\sum_{n} \\
\frac{1}{2}\end{array}$ & $\begin{array}{l}\frac{j}{3} \\
\frac{1}{3} \\
\frac{3}{3} \\
y \\
y\end{array}$ & $\begin{array}{l}\frac{7}{7} \\
\frac{7}{2} \\
\frac{8}{9} \\
\frac{8}{19}\end{array}$ & 司 & 司, & 司 & $\begin{array}{l}\overline{3} \\
\frac{3}{7} \\
\frac{7}{7} \\
\frac{10}{7} \\
3 \\
\overline{3} \\
\overline{3} \\
\bar{y} \\
y \\
y\end{array}$ \\
\hline $18 \mathrm{~s}$ & & * ${ }^{*}{ }^{\infty}$ & $* 2$ & $*$ & $* \frac{\sigma}{2}$ & 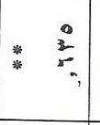 & $* \frac{2}{2}$ & 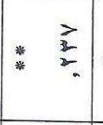 & * $\quad \stackrel{0}{0}$ & 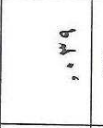 & $\begin{array}{ll}* & \frac{2}{2} \\
3 & 2 \\
2\end{array}$ \\
\hline$\vec{P} r^{\circ}$ & & & $* z_{2}^{2}$ & $* \frac{3}{2}$ & * & $* \underset{*}{*} \stackrel{m}{*}$ & $* \frac{2}{*}$ & $* \frac{0}{2}$ & $* \dot{\vdots}$ & $* \begin{array}{ll}* & 2 \\
* & 2\end{array}$ & $* \frac{2}{2}$ \\
\hline 10mis & & & & $* \quad \begin{array}{l}\dot{w} \\
z\end{array}$ & $* 2$ & $* \stackrel{0}{\stackrel{0}{*}}$ & * & 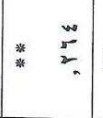 & $* \stackrel{0}{\vdots}$ & $* \frac{5}{2}$ & $* 2$ \\
\hline $\operatorname{lig}^{0} \cdot{ }^{6} \|^{m} K^{\circ}:$ & & & & & $* \quad \bar{\sigma}$ & 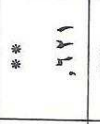 & * * & $=2$ & 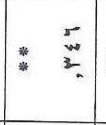 & $* \vdots$ & $* 2$ \\
\hline 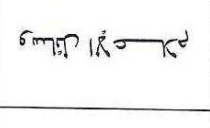 & & & & & & * ${ }_{*}^{2} \sum_{0}^{2}$ & * & * $\begin{array}{l}\infty \\
* \\
* \\
*\end{array}$ & 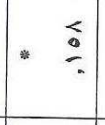 & $\frac{3}{2}$ & * \\
\hline 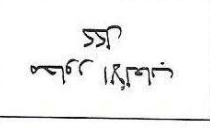 & & & & & & & * $\begin{array}{ll} & < \\
* & 2 \\
* & 0\end{array}$ & * & 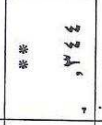 & $* \frac{5}{2}$ & \begin{tabular}{cc|} 
& $>$ \\
$*$ & $\vdots$ \\
$*$ & $\cdots$ \\
$*$ & $\cdots$
\end{tabular} \\
\hline 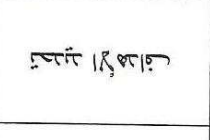 & & & & & & & & $* \leq$ & $\begin{array}{ll}3 & 2 \\
* & 0 \\
* & 0\end{array}$ & * & 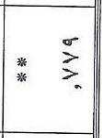 \\
\hline माप्कप्य & & & & & & & & & 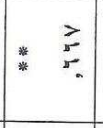 & $* \frac{2}{2}$ & 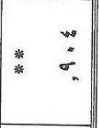 \\
\hline 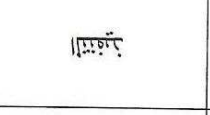 & & & & & & & & & & $*$ & * $\stackrel{\infty}{\longleftarrow}$ \\
\hline एक्षित्र & & & & & & & & & & & * $\frac{1}{2}$ \\
\hline 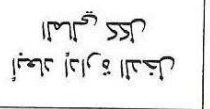 & & & & & & & & & & & \\
\hline
\end{tabular}




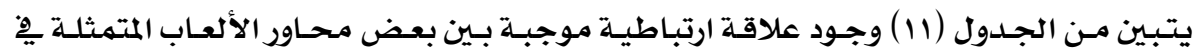

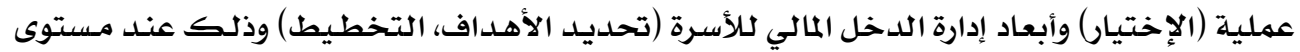

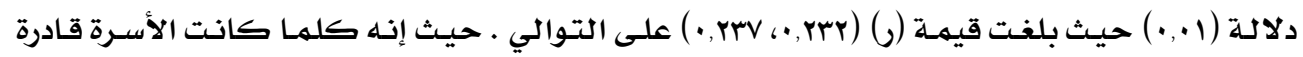

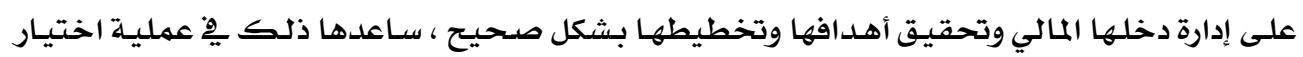

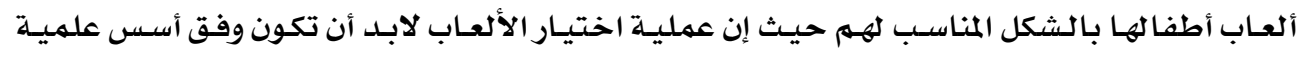

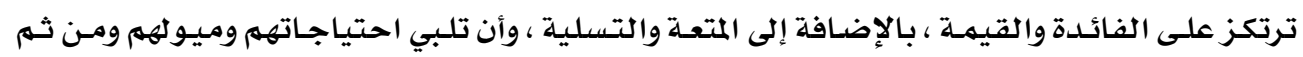

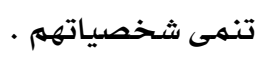

كمها يتضح مـن الجـدول (11) وجـود علاقـة ارتباطيـة موجبـة بـين شـراء الألعـاب ، وأبعـاد إدارة

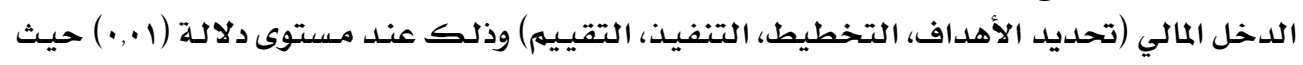

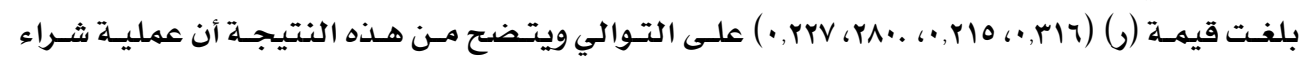

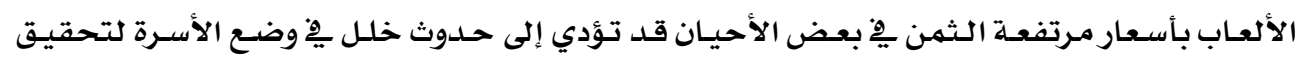

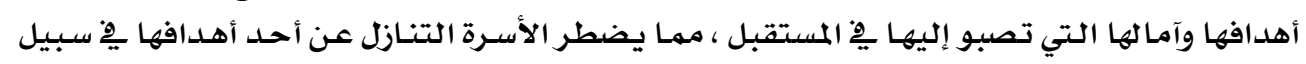
إرضاء أطفا لها .

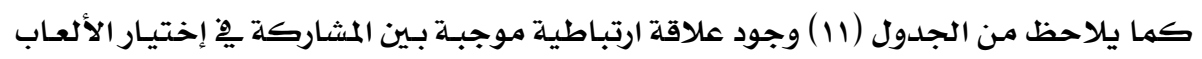

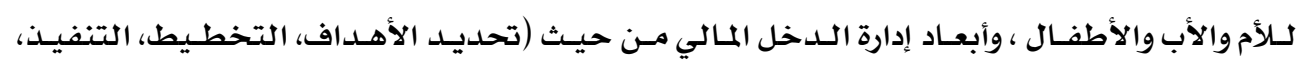

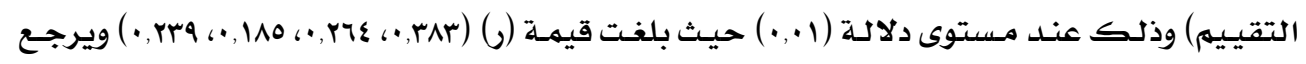

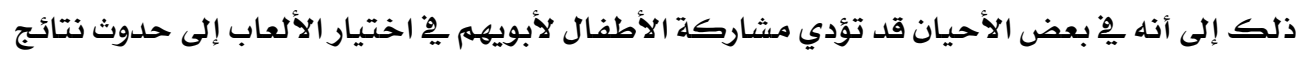

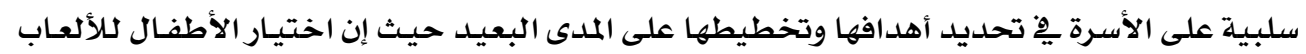

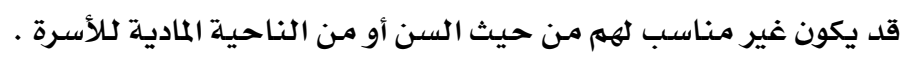

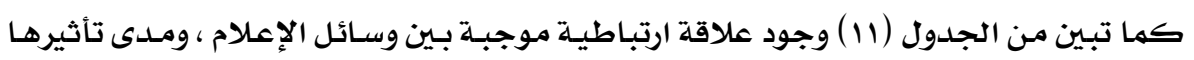

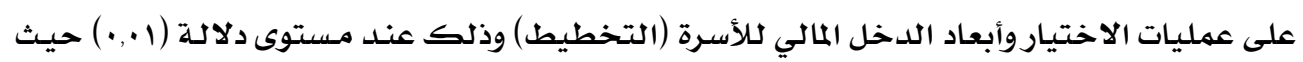

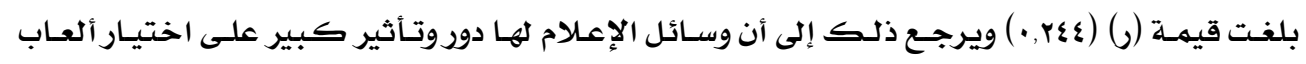

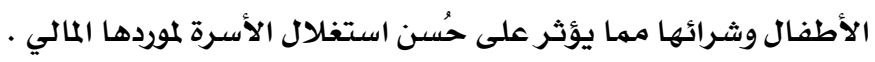

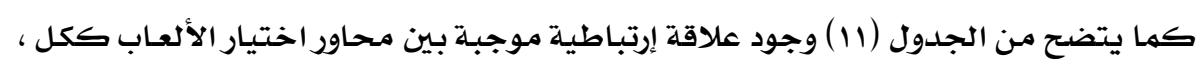

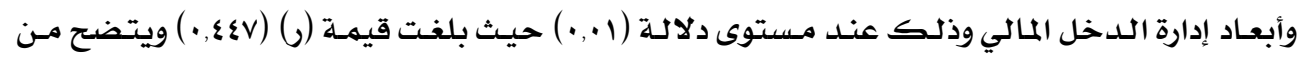

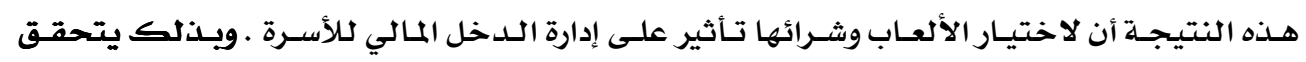

\section{هلخص النتائج:}

أسفرت نتائج الدراسة الحالية عن التالي:

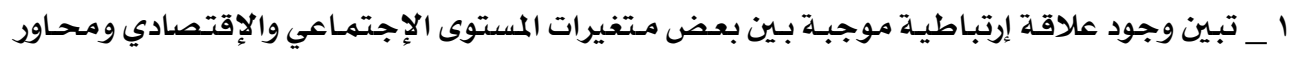

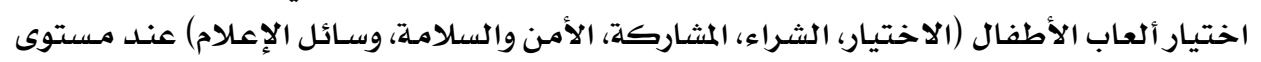

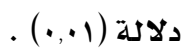


ץ _ تبـين وجـود علاقـة ارتباطيـة موجبـة بــين بعض مـتغيرات المستوى الإجتمـاعي والإقتصـادي ، وإدارة

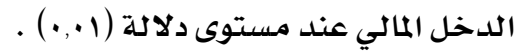

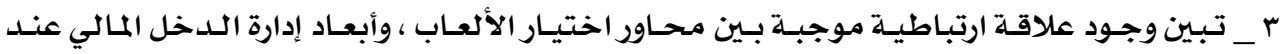

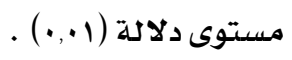

ع _ تبـين وجود علاقة ارتباطية موجبـة بـين عمـر الزوجـة ومستواهـا التعليمسي ، ومششاركتها لأطفالها

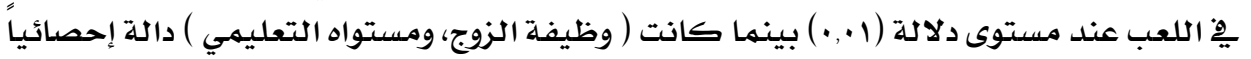
عند مستوى دلالة (0., ) ) .

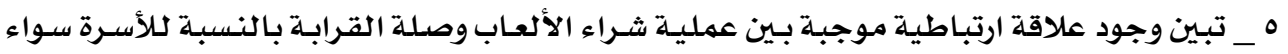

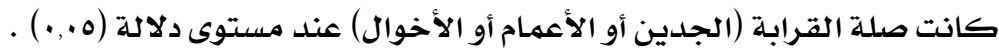

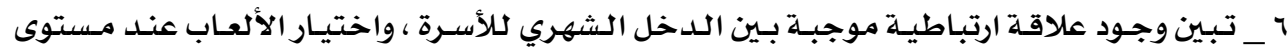

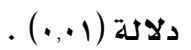

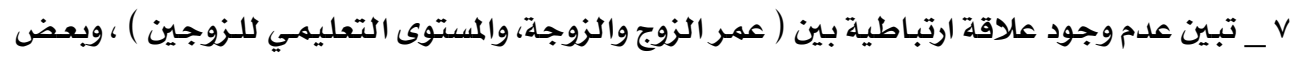

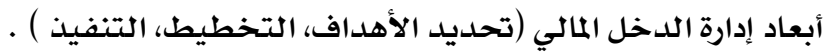

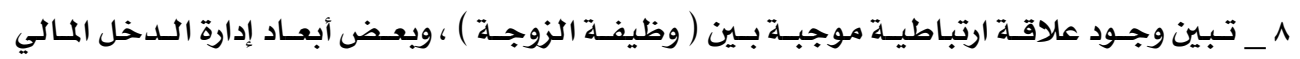

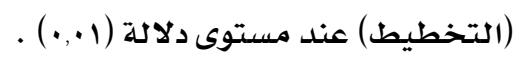

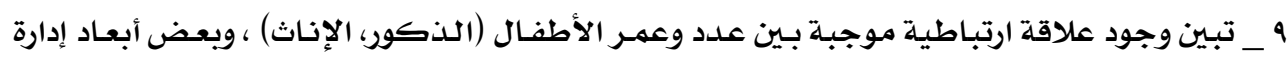

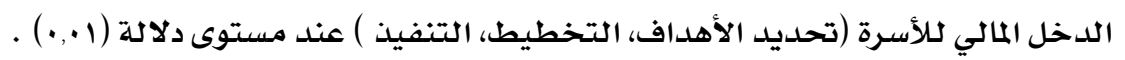

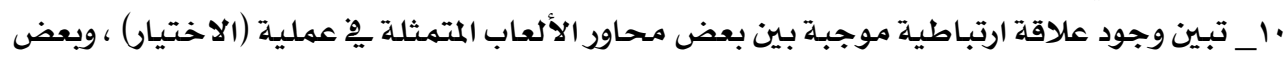

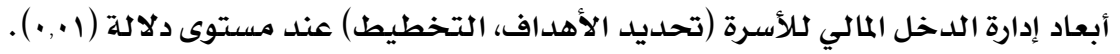

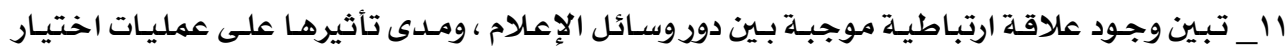

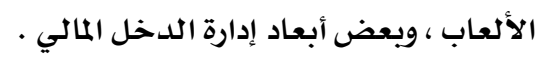

التوصيـات بناءُ على نتائج الدراسة توصى الباحثة بالتالي: ا _ تنظيم الحملات التوعويـة والاستفادة مـن وسـائل الإعلام المختلفـة (المقـروءة والمسموعة والمرئيـة)،

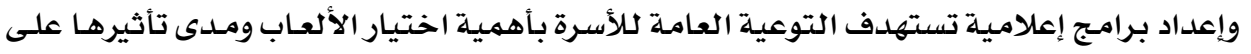
تربية وتنمية الطفل .

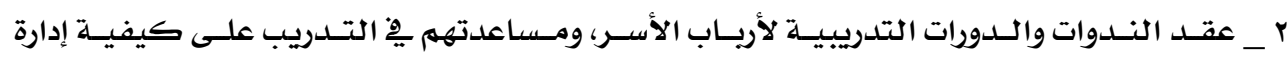

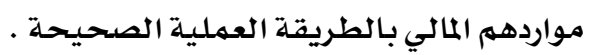

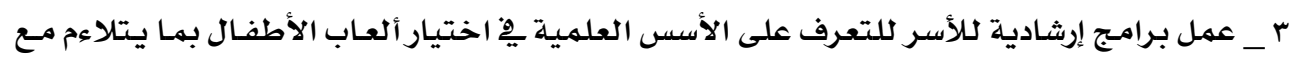

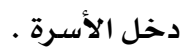

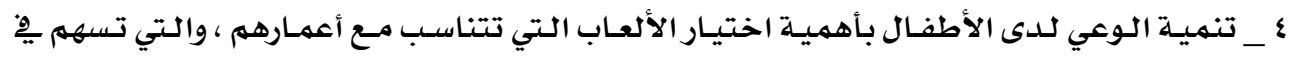
تنمية مداركه وتوسيع آفاقه . 
• _ الاهتمام بإدخال وسائل اللعب المختلفة ضمن مناهج التدريس ِِّ المرحلة الإبتدائية .

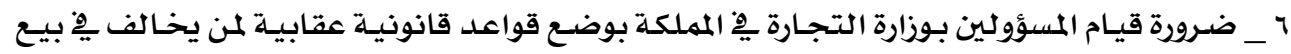
الألعاب المضرة بسلامـة الأطفال .

\section{المراجهـع}

ا- أمل عبدالرزاق صالح سلامة (ع .. r) : " أثر وجود طفل معاق بصرياً بالأسرة على تخطيط المرأة السعودية

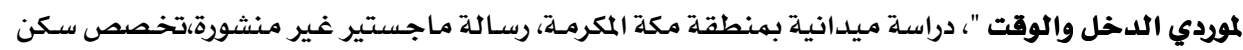

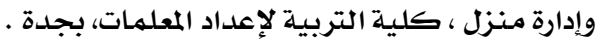

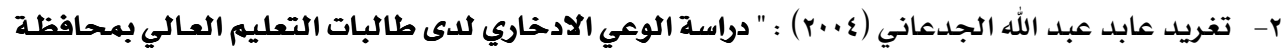

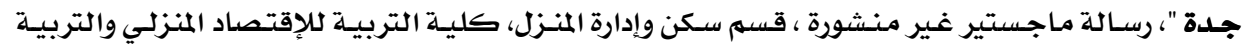

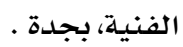

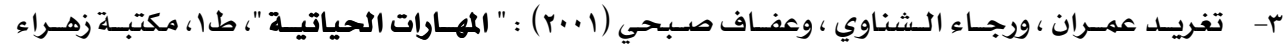
الشرق، القاهرة . ع- حنان سامي عبدالعاطي ( . . ب) : " العادات والتقاليد بالأعياد والمناسبات وأثرها على إدارة الدخل المالي

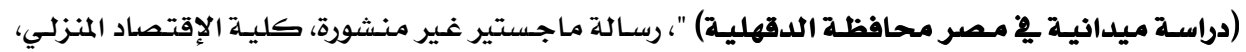

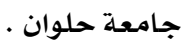

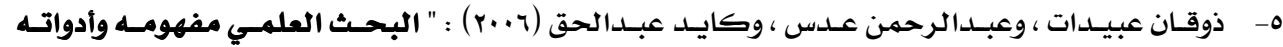

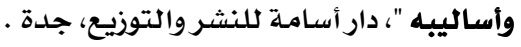

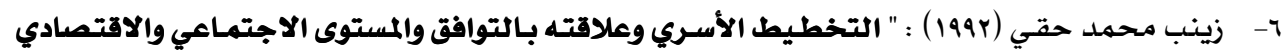

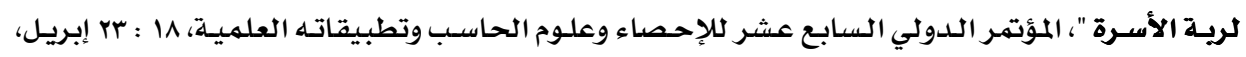

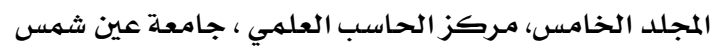

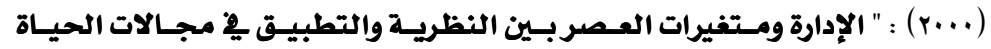

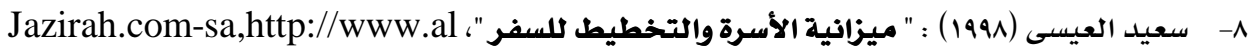

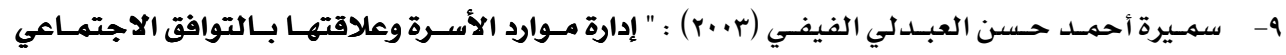

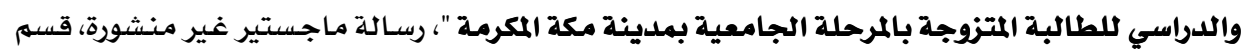

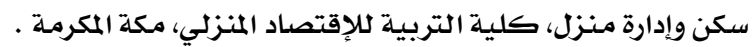

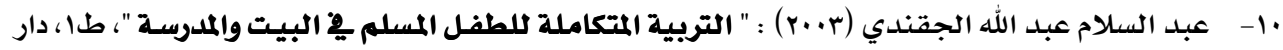

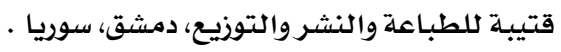

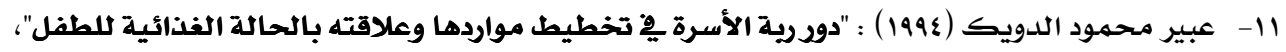

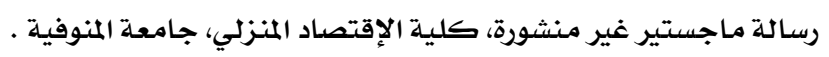

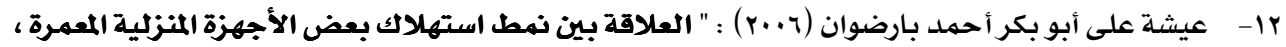

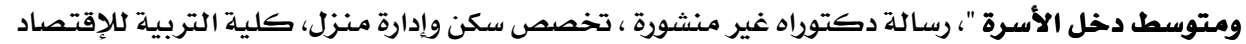




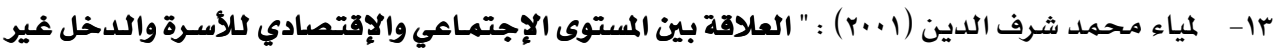

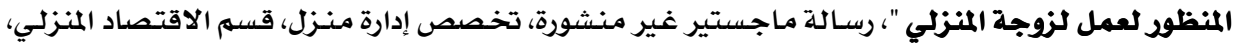

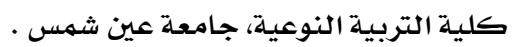

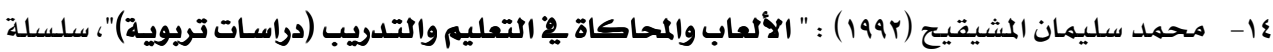

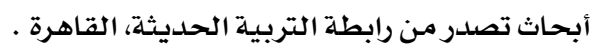

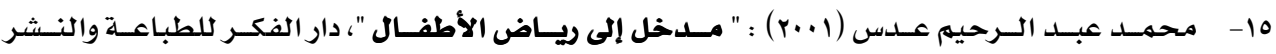
والتوزيع، الأردن .

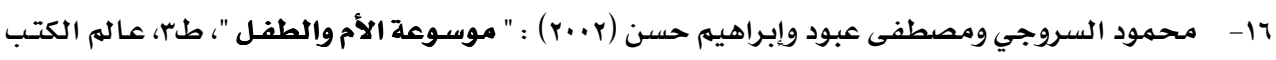
للنشر،القاهرة . محهود العروجي

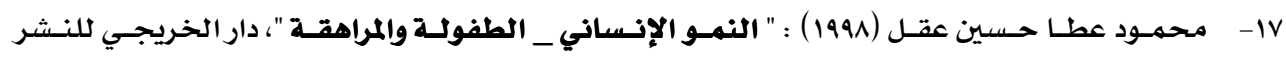

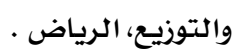

11- منى حامد موسى (1999) : " أثر استخدام بطاقات الإيتتمان على إدارة الدخل المالي للأسرة السعودية "،

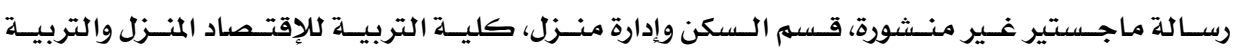
الفنية، بجدة .

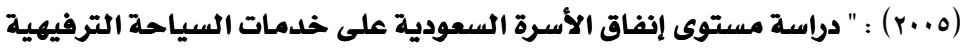
$-19$

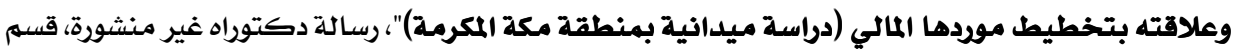

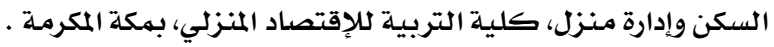

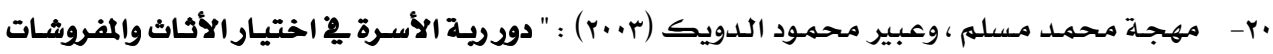

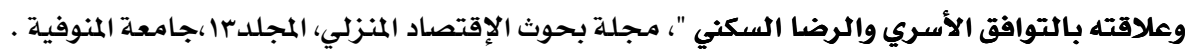

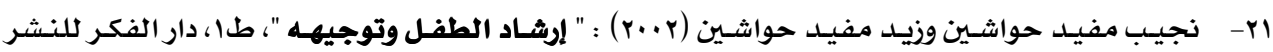
والتوزيع والطباعة، عمان

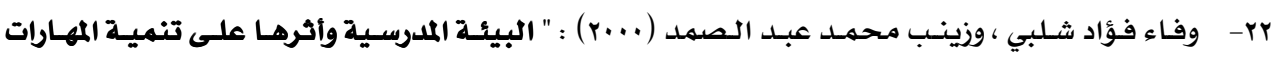

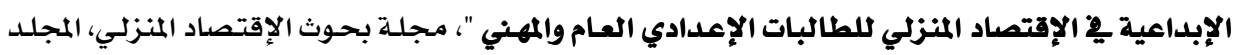

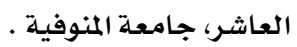

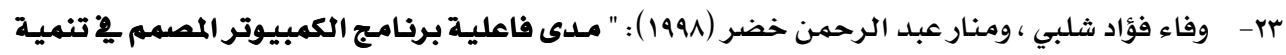

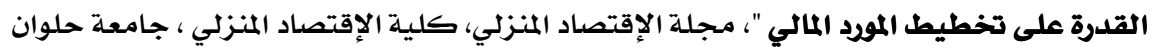

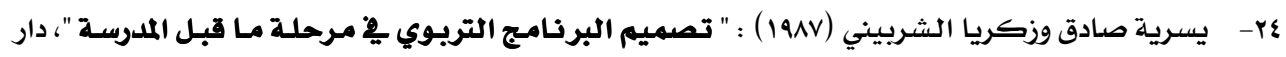
الفكر الجامعي، القاهرة .

l- Fanning, M. J. (1981) : " Home Economics Teachers, perceptions of family through four Conceptual frameworks ". Education Home Economics University of Wisconsin of Madison. Dissertation abstracts International. Vol.42, No. 2.

2- Ivan F. Bertler, Jerald W. Mason (1987) : Family Cash - Flow Budgeting. Department of 